"This document is the Accepted Manuscript version of a Published Work that appeared in final form in J.Phys. Chem. B 2016, 120 (50), 12959, copyright (C) American Chemical Society after peer review and technical editing by the publisher. To access the final edited and published work see 10.1021/acs.jpcb.6b10387."

\title{
Simulating the Favourable Aggregation of Monolacunary Keggin Anions
}

\author{
Stefano Artin Serapian ${ }^{\dagger}$ and Carles Bo ${ }^{\dagger, \ddagger}$ \\ ${ }^{\dagger}$ Institute of Chemical Research of Catalonia (ICIQ), The Barcelona Institute of Science and Technology, \\ Av. Països Catalans 16, 43007 Tarragona, Spain \\ *Departament de Química Física i Inorgànica, Universitat Rovira i Virgili, \\ Marcel·lí Domingo s/n, 43007 Tarragona, Spain \\ *Corresponding author: cbo@iciq.es
}

\begin{abstract}
We here present a series of classical molecular dynamics simulations (MD) on aqueous solutions of the $\mathrm{salts}_{\mathrm{Li}} \mathrm{i}_{5} \mathrm{AlW} \mathrm{W}_{12} \mathrm{O}_{40}$ and $\mathrm{Li}_{9} \mathrm{AlW} \mathrm{W}_{11} \mathrm{O}_{39}$, providing us with valuable insight on their aggregative behaviour. Analysis of relative dipole moment orientation in pairs of aggregated $\left[\mathrm{AlW} \mathrm{W}_{11} \mathrm{O}_{39}\right]^{9-}$ excludes that their large dipole moment is behind their greater propensity to aggregate. On the other hand, MD simulations of the aqueous $\mathrm{Li}^{+}$salt of the fictitious $\left[\mathrm{AlW} \mathrm{W}_{12} \mathrm{O}_{40}\right]^{9-}$-as high in charge as $\left[\mathrm{AlW} \mathrm{W}_{11} \mathrm{O}_{39}\right]^{9-}$, but lacking dipole moment and tetrahedral in shape like $\left[\mathrm{AlW} \mathrm{W}_{12} \mathrm{O}_{40}\right]^{5-}$-reveal that it is in fact the higher negative charge itself that promotes aggregation, by allowing to recruit a higher number of $\mathrm{Li}^{+}$countercations, which then act as an electrostatic glue. The lower charge on $\left[\mathrm{AlW}_{12} \mathrm{O}_{40}\right]^{5-}$, on the other hand, is not able to muster enough $\mathrm{Li}^{+}$countercations for it to aggregate favourably.
\end{abstract}

\section{Introduction}

Prominent members of the polyoxometalate (POM) family, plenary Keggin anions (PKAs) have been known since at least $1826 .{ }^{1} \quad$ Also defined as heteropolyanions, they have general formula $\left[\mathrm{XM}_{12} \mathrm{O}_{40}\right]^{q-}$; where $q$ - is normally a high negative charge; $\mathrm{M}$ is a transition metal in high oxidation state (typically $\mathrm{Mo}^{\mathrm{VI}}$ or $\mathrm{W}^{\mathrm{VI}}$ ); and the central heteroatom $\mathrm{X}$ is often one of $\mathrm{Al}^{\mathrm{III}}, \mathrm{Si}^{\mathrm{IV}}$, or $\mathrm{P}^{\mathrm{V}}$, but may also be of another element such as $\mathrm{Ge}^{\mathrm{IV}}, \mathrm{Fe}^{\mathrm{III}}$, or $\mathrm{Co}^{\mathrm{II}}$. As early as $1933{ }^{2}$ working with X-ray diffraction and the anion $\left[\mathrm{PW}_{12} \mathrm{O}_{40}\right]^{3-}$, Keggin was able to resolve the characteristic tetrahedral structure of PKAs in their $\alpha$-form (Figure 1a): a central tetrahedron $\left[\mathrm{XO}_{4}\right]$, surrounded by a $\left[\mathrm{M}_{12} \mathrm{O}_{40}\right]$ outer cage, wherein each of the metal atoms is coordinated by six oxygen atoms (one always coming from the central $\left[\mathrm{XO}_{4}\right]$ ).

(a)

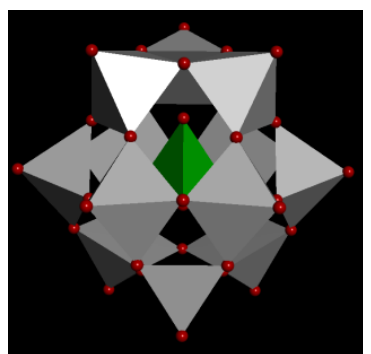

(b)

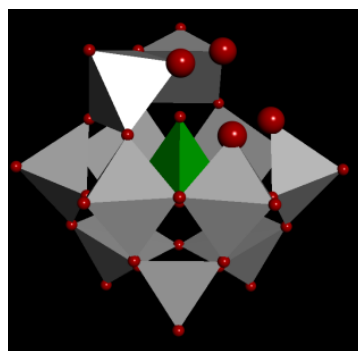

Figure 1. Typical general structures of (a) a PKA; and (b) a MKA, in their $\alpha$-form. Both are rendered as polyhedra. Key: red spheres: O; white polyhedra: M; green polyhedra: $\mathrm{X}$. $\mathrm{O}$ atoms forming the $\left[\mathrm{O}_{4}\right]$ lacuna in (b) are larger in size.

Monolacunary Keggin anions (MKAs), on the other hand, have general formula $\left[\mathrm{XM}_{11} \mathrm{O}_{39}\right]^{(q+r)-}$, and were only first reported almost a century and a half later: ${ }^{3}$ with respect to PKAs, they are formally missing one $[\mathrm{M}=\mathrm{O}]^{r+}$ unit from their outer cage, which is replaced by a rectangular $\left[\mathrm{O}_{4}\right]$ lacuna (Figure $1 \mathrm{~b}$ ). Aside from lowering overall symmetry and charge, the lacuna introduces a large dipole moment, which is perpendicular to its own plane (cf. Figure 2 for $\left[\mathrm{AlW}_{11} \mathrm{O}_{39}\right]^{9-}$; vide infra). 
PKAs and MKAs of varying atomic composition are currently known for a series of highly desirable chemical characteristics, all comprehensively documented: ${ }^{4,5}$ these comprise their prominent redox and catalytic activity; ${ }^{6}$ their magnetic behaviour, ${ }^{7,8}$ as well as applications in sensing, ${ }^{9}$ biology, ${ }^{10,11}$ and optoelectronics. ${ }^{12,13}$

In addition, the rectangular lacuna in MKAs represents an ideal binding site wherein to anchor a variety of functional moieties and/or linkers: ${ }^{14-17}$ in practice, this somewhat broadens MKAs' versatility with respect to that of PKAs. Notable examples are organic tethers to chromophores; ${ }^{12,18,19}$ to (photo)catalytic centres; ${ }^{13,20-22}$ to other solid supports such as electrodes, silica, and metal oxides; ${ }^{9,19,23-26}$ and to distal metal chelating centres, for subsequent incorporation in co-ordination polymers. ${ }^{26,27}$

Just as significant as these intrinsic chemical properties is the dynamic behaviour of Keggin anions in solution. Of particular relevance are their electrostatic interactions with different countercations; with individual solvent molecules; and between themselves as a function of their elemental composition.

Effects of such interactions are experimentally well documented, not just in Keggin anions, but in other POMs too. Firstly, in aqueous medium, mere variations in the chosen countercation may favour or preclude a particular synthetic route ${ }^{28-31}$ affect isomeric stability; ${ }^{32}$ and even mutate the redox properties themselves. ${ }^{33}, 34$ Secondly, dynamic electrostatic interactions are certain to play a primary role in the supramolecular applications of POMs. These include encapsulation into dendrimers, ${ }^{35,}{ }^{36}$ surfactants, ${ }^{37}$ and cyclodextrins; ${ }^{38}$ their use in ionic liquids; $; 9-42$ as well as their noncovalent aggregation on surfaces ${ }^{43,44}$ and as vescicles, ${ }^{45-48}$ which occurs notwithstanding their high negative charge.

Given their rich chemistry and range of applications, it is unsurprising that properties of novel PKAs and MKAs have been the focus of many additional studies, both experimental and computational. ${ }^{49}$ If, on the one hand, static QM calculations have proven essential to investigate intrinsic properties such as structural stability, ${ }^{50-55}$ electronic structure ${ }^{56-60}$ reactivity, ${ }^{61,62}$ and spectroscopic signature; ${ }^{63}$ it is equally true that classical MD simulations of Keggin salt solutions are an obligatory choice if one wishes to better elucidate their dynamic properties at the nanoscale. As such, their use alongside experiment is becoming increasingly common.

For example, Brodbeck et al. ${ }^{64}$ have carried out MD simulations of dendrimer-encapsulated $\alpha$-PKAs. ${ }^{35}$ In another study, López et al. ${ }^{65}$ have reported simulations of the $\alpha$-PKA salt $\mathrm{Na}_{3} \mathrm{PW}_{12} \mathrm{O}_{40}$ in water, carrying out a detailed analysis of the distribution and orientation of water molecules at different sites around the anion. Three years later ${ }^{66}$ the group reprised their work, covering the counterions $\mathrm{Li}^{+}$and $\mathrm{K}^{+}$; and the $\alpha$-PKAs $\left[\mathrm{SiW}_{12} \mathrm{O}_{40}\right]^{4-}$ and $\left[\mathrm{AlW}_{12} \mathrm{O}_{40}\right]^{5-}$ : examination of ion pairs revealed important differences in $\mathrm{Li}^{+} \cdots$ PKA contacts with respect to $\mathrm{Na}^{+} \cdots \mathrm{PKA}$ and $\mathrm{K}^{+} \cdots \mathrm{PKA}$. Together with PKA charges, these have a complex, experimentally consistent ${ }^{33,34}$ influence on PKA diffusion coefficients.

Also of great relevance is the prolific work undertaken by Chaumont and Wipff to study PKA aggregation. ${ }^{67-69}$ In $2008,{ }^{67}$ the authors first presented MD simulations of mono- and polyvalent cation salts of $\alpha-\left[\mathrm{PW}_{12} \mathrm{O}_{40}\right]^{3-}$, in water and methanol, at different concentrations. Studies were extended in $2012^{68}$ to cover different water and $\alpha-\left[\mathrm{PW}_{12} \mathrm{O}_{40}\right]^{3-}$ models; and finally, in $2013,{ }^{69}$ to encompass $\alpha-\left[\mathrm{SiW}_{12} \mathrm{O}_{40}\right]^{4-}, \alpha-\left[\mathrm{AlW}_{12} \mathrm{O}_{40}\right]^{5-}$, and additional cations. On top of reasserting the complex nature of the interactions between various PKAs and countercations, ${ }^{66}$ the authors did indeed observe PKA aggregation as a function of concentration, PKA charges, and cation type (albeit rarely surviving beyond 0.5-0.8 ns): cations were seen to mediate aggregation by crucially overcoming the negative charge on PKAs, effectively "gluing" them together.

More recently, Bera, Antonio and coworkers ${ }^{70}$ have studied aggregation of PKAs in aqueous solutions at relatively low $\mathrm{pH}$, both through experiments and atomistic MD simulations. In particular, having explored the series $\left[\mathrm{PW}_{12} \mathrm{O}_{40}\right]^{3-}$, $\left[\mathrm{SiW}_{12} \mathrm{O}_{40}\right]^{4-}$ and $\left[\mathrm{AlW}_{12} \mathrm{O}_{40}\right]^{5-}$ experimentally the authors observed, in contrast to previous studies ${ }^{68}$ that the extent of aggregation actually decreased as a function of increasing PKA negative charge. Aggregates formed during the simulations, featuring $\left[\mathrm{PW}_{12} \mathrm{O}_{40}\right]^{3-}$ only, are clearly seen to be held together, transiently, by a web of $\mathrm{H}_{3} \mathrm{O}^{+}$ions. Similar studies reported by Mei et al. ${ }^{71}$ have addressed the issue of aggregation in ionic liquids in solution, highlighting the continued interest in the topic. 


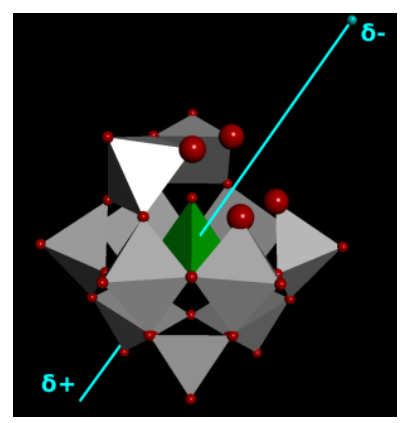

Figure 2. Representation of the dipole moment $\mu$ present in $\mathbf{2}$, shown in turquoise: the vector (not to scale) is plotted through the central atom and centre of mass, and is almost perpendicular to the plane of the $\left[\mathrm{O}_{4}\right]$ lacuna. Key: same as Figure $1 \mathrm{~b}$, but with $\mathrm{X}=\mathrm{Al}$ and $\mathrm{M}=\mathrm{W}$.

Herein, with the aim of investigating aggregation, we present several MD simulations featuring solutions of $\mathrm{Li}_{5} \mathbf{1}$, as well as, for the first time, $\mathrm{Li}_{9} 2$, and the $\mathrm{Li}^{+}$salt of the fictitious PKA $\left[\mathrm{AlW}_{12} \mathrm{O}_{40}\right]^{9-}\left(\mathrm{Li}_{9} \mathbf{3}\right)$, which shares 2's charge but lacks its dipole moment $\mu$. First, we examine whether 2's distinctive $\mu$ (Figure 2), absent in $\mathbf{1}$ and $\mathbf{3}$, is implicated in any way. Then, we consider the alternative hypothesis that it is the higher negative charge on $\mathbf{2}$ and $\mathbf{3}$ alone that, regardless of $\mu$, is paradoxically enough to drive aggregation by better harnessing the $\mathrm{Li}^{+}$cations.

We begin our report with a brief overview about how our MD simulations are set up and run. We then go on to present their outcome, assessing: aggregation in $\mathbf{1}$ and $\mathbf{2}$; relative $\mu$ orientation in pairs of $\mathbf{2}$; then again aggregation in $\mathbf{3}$; and $\mathrm{Li}^{+}$distribution around 1-3. Thereafter, we discuss the impact of these analyses on our initial hypotheses, and finally present our conclusions.

\section{Computational Details}

\section{Generation of input geometries for 1,2 and 3}

For the PKA 1 and MKA 2, geometries employed in our MD simulations are obtained after prior optimisation with the Gaussian09 software package, ${ }^{72}$ using spin restricted density functional theory (BP86 functional): ${ }^{73,74}$ tungsten electrons are modelled with the LANL2DZ effective core potential and basis set; ${ }^{75}$ remaining ones are treated with the 6$311 \mathrm{G}(\mathrm{d}, \mathrm{p})$ basis set. Water effects are accounted for implicitly, using the polarised continuum solvation model. ${ }^{76}$ For the fictitious PKA 3, we adopt the same input geometry found for its real counterpart $\mathbf{1}$.

\section{Forcefield Details}

Forcefield parameters used to treat ions and molecules in our MD simulations comprise: atomic point charges $q$; Lennard-Jones (LJ) parameters $\sigma$ and $\varepsilon$; and equilibrium bonded parameters for water, 1, 2, and 3. All such parameters are provided in full as Supporting Information, including those derived or assigned ad hoc for 1, 2, and 3, which involve harmonic distance constraints, and thus require a more detailed discussion. Any undefined LJ parameters are assigned using the Lorentz-Berthelot combination rules, also reported as Supporting Information.

Indeed, forcefield parameters used for water and lithium cations, are readily available and applicable. Lithium cations are treated with the parameter set reported by Dang in $1992 .{ }^{77}$ Water molecules are instead modelled according to TIP4P specifications, ${ }^{78}$ and kept rigid during MD simulations by means of SETTLE constraints. ${ }^{79}$

The combination of these sets of parameters leads to a good qualitative reproduction of $\mathrm{Li}^{+}$'s predominant hydration structure $\mathrm{Li}\left(\mathrm{OH}_{2}\right)_{4}{ }^{+}$, with water molecules forming a distorted tetrahedron. ${ }^{77,80}$ For further considerations on the hydration structure of $\mathrm{Li}^{+}$in the vicinity of Keggin anions and their aggregates, the reader is again referred to the Supporting Information.

\section{Approach}

Aggregation of 1, 2, and later 3, is investigated by running a series of classical molecular dynamics (MD) simulations, on six distinct systems: two independently set up $\mathrm{Li}_{5} \mathbf{1}$ solutions (henceforth $\mathbf{1 - A}$ and $\mathbf{1 - B}$ ); two independently set up $\mathrm{Li}_{9} \mathbf{2}$ solutions (2-A and 2-B); and two independently set up $\mathrm{Li}_{9} \mathbf{3}$ solutions (3-A and $\left.\mathbf{3}-\mathbf{B}\right)$. All simulations are carried 
out using the GROMACS 5.0.2 package, ${ }^{81,82}$ under periodic boundary conditions, and with a Keggin anion concentration of $0.026 \mathrm{M}$. Further details and snapshots concerning the preparation of these independent setups are provided as Supporting Information.

General conditions and procedure. All simulations are carried out at a temperature of $300 \mathrm{~K}$, enforced with the Berendsen thermostat. ${ }^{83}$ In virtue of the constraints imposed on 1, 2, and 3 (Supporting Information), these require coupling to the thermostat with a shorter time constant $\left(\tau_{T}\right)$ of $20 \mathrm{fs}$; a $\tau_{T}$ of 1 ps is sufficient for remaining molecules. For computing LJ and Coulomb interactions, we impose a cut-off of $1.7 \mathrm{~nm}$ : Coulomb interactions beyond this limit are corrected using the Particle Mesh Ewald method. ${ }^{84}$ Equations of motion are solved using the leap-frog integrator ${ }^{85}$ (time step: $0.5 \mathrm{fs})$.

First of all, two equilibration-only simulations are run on each of the six systems 1-A, 1-B, 2-A, 2-B, 3-A, and 3-B (Stages I and II); there follows a final Stage III, which combines equilibration and production. Details of individual stages are as follows:

I. $10 \mathrm{~ns}$ in the $N V T$ ensemble; with position restraints enforced on Keggin anions; but solvent and cations free to move;

II. $10 \mathrm{~ns}$ as above, but this time at constant pressure instead of constant volume $(1 \mathrm{bar}$, enforced with the Berendsen barostat) $;{ }^{83}$ and

III. $40 \mathrm{~ns}$ (1 ns equilibration plus $39 \mathrm{~ns}$ production), again at constant pressure and temperature, with all position restraints lifted.
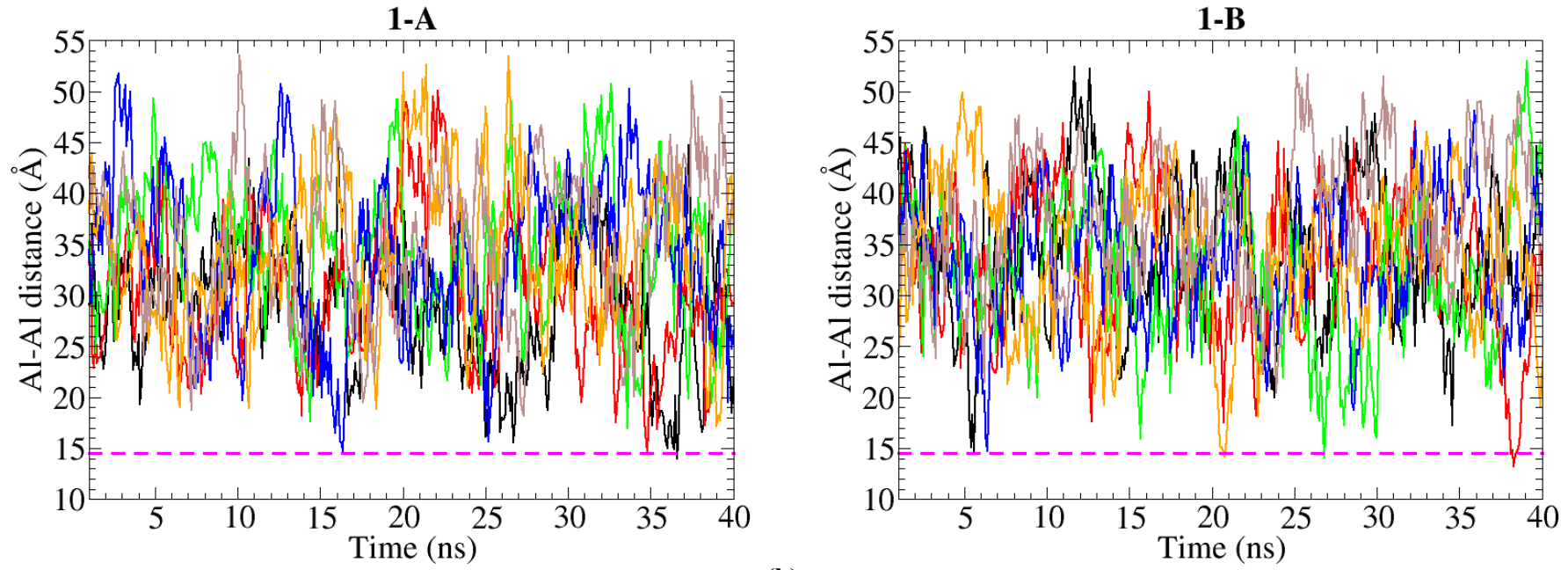

(a)

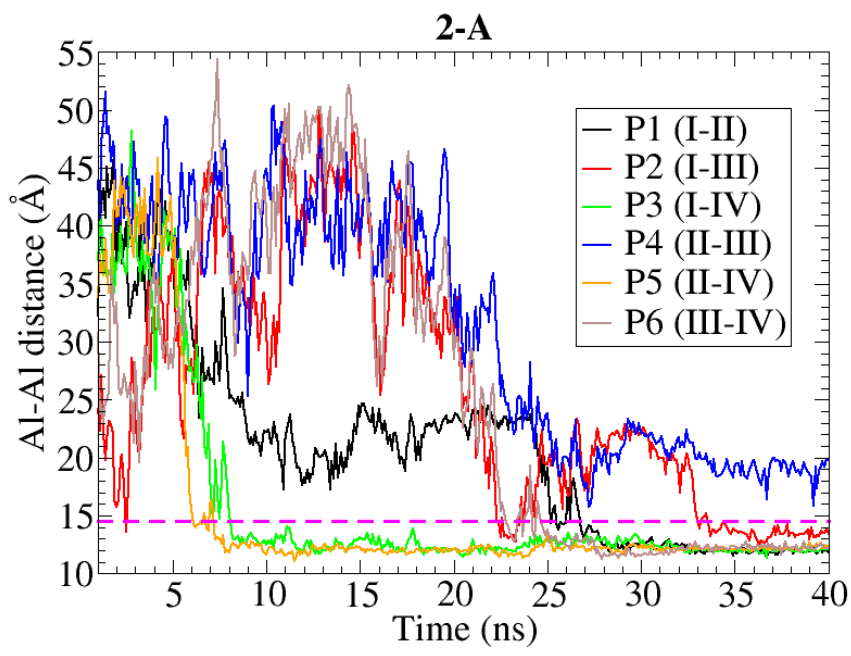

(c)

Figure 3. Evolution of Keggin-Keggin distances in independent systems (a) 1-A; (b) 1-B; (c) 2-A; and (d) 2-B; during the last 39 ns of MD simulation (Stage III; $1-40 \mathrm{ns)}$ ), and as measured from each Keggin's aluminium centre. The four specimens of $\mathbf{1}$ or $\mathbf{2}$ present in each system (identifiable as 1I-1IV and 2I-2IV respectively), give rise in each case to six individual Keggin-Keggin pairs, numbered P1-P6; hence six aluminium-aluminium distances ( $c f$. universal colour code and nomenclature in (c)). Dotted magenta lines denote the $14.5 \AA$ threshold below which aggregation is considered to occur (see Supporting Information). Distances are sampled every 100 ps. 0 - 1 ns (equilibration) not shown. 
Post-MD analysis is thus always carried out on the last 39 ns of Stage III. Aside from visual inspection of the trajectories (carried out with the package $V M D$ ), ${ }^{86}$ this includes: monitoring Keggin-Keggin distances to quantify aggregation; assessment of relative dipole moment orientation in selected MKA pairs; and quantification of the number of $\mathrm{Li}^{+}$cations free in solution, of those with a single Keggin anion neighbour, and those sharing two or more Keggin anion neighbours. Where necessary, further information for each of these procedures is given in Results and Discussion, and as Supporting Information.

\section{Results}

\section{Assessing aggregation in 1 and 2}

We set out to quantify aggregation in the four independent systems featuring real Keggin anions (i.e. 1-A, 1-B, 2-A, and 2-B). Each of these four systems contains four individual instances of PKA 1 or MKA 2 (henceforth referred to as 1I 1IV and 2I - 2IV), giving rise in each case to six distinct Keggin-Keggin pairs (labelled P1 - P6; with P1 formed by Keggins I and II; P2 by I and III; and so on).

Aggregation is probed by monitoring the evolution of the six distances associated with P1 - P6 in 1-A, 1-B, 2-A, and 2-B, as measured between aluminium centres, over the last $39 \mathrm{~ns}$ of Stage III (production). Resulting plots, with Keggin-Keggin distances sampled every 100 ps, are illustrated in Figure 3. Although it is not shown in the Figure, we note that the equilibration part of Stage III $(0-1 \mathrm{~ns})$ is still included in the overall count of time: as a result, all simulation times quoted in the text will include this extra nanosecond.

We consider any pair of Keggin anions to have aggregated whenever its corresponding distance in these plots falls below the arbitrary threshold of $14.5 \AA$ (marked in all Figure 3 panels). Its choice is documented in Supporting Information.

A glance at Figure 3 immediately reveals some obvious differences between the fate of PKAs 1I - 1IV (top) and that of MKAs 2I - 2IV (bottom), as well as evident similarities between independent MD runs on "A" systems and "B" systems.

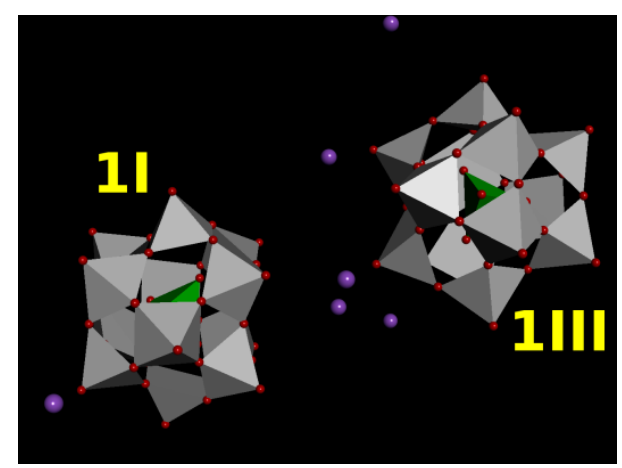

Figure 4. Transient PKA aggregate arising in 1-B during the production stage of its MD simulation (snapshot at $38.6 \mathrm{~ns}$ ), surviving for $200 \mathrm{ps}$. Key: same as Figure 2, with nearby $\mathrm{Li}^{+}$additionally rendered as purple spheres. Water molecules and distal $\mathrm{Li}^{+}$omitted for clarity.

In the case of systems 1-A and 1-B (Figure 3a and b), all PKA-PKA distances are seen to fluctuate quite uniformly for the entire duration of Stage III, signalling an almost complete lack of aggregation; this is amply confirmed by visual inspection of the trajectories. The aggregation threshold is passed only twice in 1-A (P4 at $16.4 \mathrm{~ns}$ and P1 at $36.4 \mathrm{~ns}$ ); and thrice in 1-B (P5 at $20.8 \mathrm{~ns}, \mathrm{P} 3$ at $26.8 \mathrm{~ns}$, and P2 at $38.1-38.4 \mathrm{~ns}$ ); with a few more "close calls" in both. Almost all of these episodes are highly transient: allowing for a 99 ps uncertainty on either side of every sampled point, one can assume that none of these aggregates survives for longer than $\sim 200 \mathrm{ps}$, except the last one (P2 in 1-B; shown at $38.6 \mathrm{~ns}$ in Figure 4), which survives for between $\sim 300$ ps and $\sim 500$ ps. 


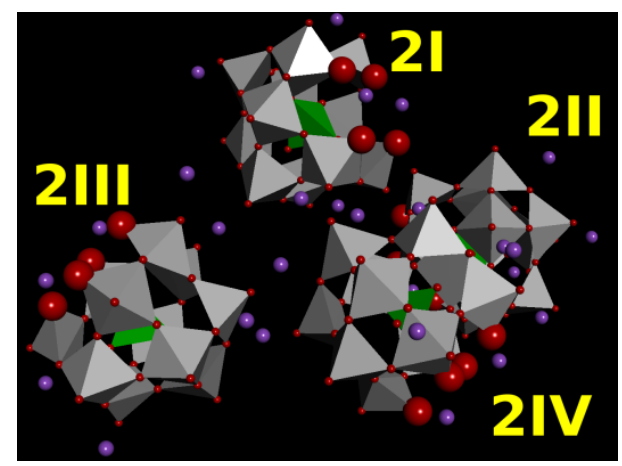

Figure 5. Bent rhomboidal quaternary MKA aggregate (2I-2IV)-(2III-2II) arising in 2-A at the end of the production stage of its MD simulation (40 ns). Key: same as Figure 4, with water molecules and distal $\mathrm{Li}^{+}$again omitted for clarity. Lacunary oxygens rendered as larger spheres.

On the other hand, distance plots for 2-A and 2-B (Figure 3c and d) paint an entirely different picture, with stable MKA-MKA aggregates already forming in the earliest stages of Stage III, and still surviving at $40 \mathrm{ns.} \mathrm{Again,} \mathrm{visual}$ inspection fully confirms this for both 2-A (Figure 5) and 2-B (Figure 6).

More in detail, for 2-A, the P5 distance plot (Figure 3c) shows that a binary aggregate 2II-2IV has already formed after $6.1 \mathrm{~ns}$ (after a transient episode between $2 \mathrm{I}$ and $2 \mathrm{III}$ at $2.5 \mathrm{~ns}$ ). $2.1 \mathrm{~ns}$ later, at $8.2 \mathrm{~ns}$, this 2II-2IV aggregate is joined by 2I ( $c f$. P1 and P3 plots) to form a ternary aggregate 2I-2IV-2II: as evidenced by its snapshot at 16 ns (Figure S3a; Supporting Information), this roughly takes the shape of an obtuse triangle. Finally, at $22.8 \mathrm{~ns}$ (cf. P2 and P6 plots), even the missing MKA 2III is recruited, thus generating a quaternary aggregate. Although 2III initially approaches 2I-2IV-2II between 2I and 2IV, it temporarily loses contact with 2I ( $23.7 \mathrm{~ns}-33.1 \mathrm{~ns})$ to produce an almostplanar Y-shaped aggregate ( $c f$. snapshot at $30 \mathrm{~ns}$ in Figure S3b); eventually, however, the quaternary aggregate reacquires its "bent rhombus" shape, which it retains until the very end of Stage III (snapshot at 40 ns in Figure 5).

(a)

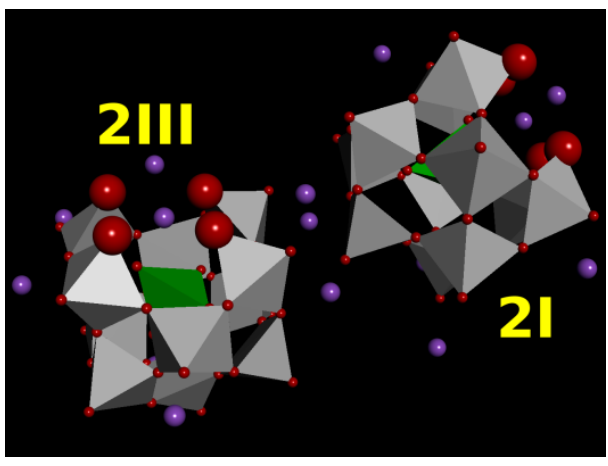

(b)

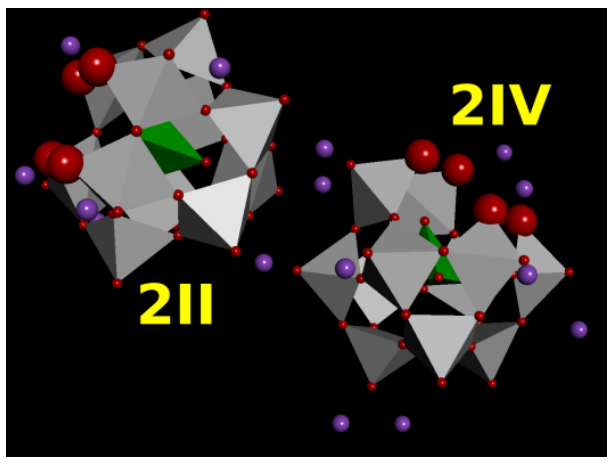

Figure 6. MKA aggregates arising in 2-B during the production stage of its MD simulation, as evidenced by snapshots at $40 \mathrm{~ns}$ of: (a) the binary aggregate 2I-2III; and (b) 2II-2IV. Key: same as Figure 4, with water molecules and distal $\mathrm{Li}^{+}$omitted for clarity. Lacunary oxygens rendered as larger spheres.

Aggregation also clearly occurs in 2-B (Figure 3d), albeit limitedly to two binary aggregates 2I-2III and 2II-2IV, both of which persist until the end of Stage III (Figure 6) without approaching one another. Once again, formation of 2I-2III (Figure 6a) is observed almost immediately, at $1.6 \mathrm{~ns}$ ( $c f$. P5 distance plot); formation of 2II-2IV (Figure 6b) takes a while longer, occurring transiently between $21.5 \mathrm{~ns}$ and $23.7 \mathrm{~ns}$, and then stably surviving until the end of the simulation at $40 \mathrm{~ns}$ ( $c f . \mathrm{P} 2$ distance plot). 


\section{Dipole Moment Orientation in Selected Pairs of 2}

In this next step of our analysis we set out to investigate whether, as per the first of our initial hypotheses, the dipole moment present in $\mathbf{2}(\sim 12 \mathrm{D}$ in this specific case) is effectively playing a role in its aggregation.

To this end, we monitor the relative orientation of dipole moments $\mu$ in selected MKA pairs (two each from 2-A and 2-B; vide infra), and plot how it evolves during the course of the MD production stage (Figure 7); the orientation of dipole moments within a pair of MKAs is "quantified" as $|\cos \theta|$ (see right-hand $y$-axes in Figure 7), where $\theta$ is the angle formed by the individual dipole moment vectors (details in Supporting Information). As such, its upper limit $|\cos \theta|=1$ indicates parallel or antiparallel dipole moment orientation within a pair, distinguishable by visual inspection; whereas the lower limit $|\cos \theta|=0$ denotes perpendicular orientation. To better spot any changes arising upon aggregation, each of these $|\cos \theta|$ plots is overlaid onto the corresponding distance plot of its parent MKA pair from Figure 3c or Figure 3d (see left-hand $y$-axes in Figure 7).

From 2-A, the first pair whose dipole orientation we choose to monitor is P5 (Figure 7a): its constituent anions 2II and 2IV are the first to make stable contact, remaining close together whilst their aggregate grows in size (Figure S3 and Figure 5). The second chosen pair is P6 (Figure 7b), since 2III is the last anion to approach the aggregate, and thereafter remains in contact with 2IV despite changes in the aggregate's shape ( $c f$. Figure S3b and Figure 5). Choices from 2-B are more straightforward: P2 (Figure 7c) forming the binary aggregate 2I-2III in Figure 6a; and P5 (Figure 7d), forming the binary aggregate 2II-2IV in Figure 6b.

All of the graphs in Figure 7 indicate that direct involvement of dipole moments in the aggregation of 2 is either inexistent or very feeble. The only trait common to all graphs, even for a tiny portion of Figure $7 \mathrm{~d}$, are the fairly regular fluctuations of $|\cos \theta|$ between 0 and $1\left(0^{\circ} \leq \theta \leq 180^{\circ}\right)$ observed in pairs before aggregation: this is indeed what one would expect from freely rotating molecules of 2 .

To assess in greater detail the changes in orientation patterns emerging upon aggregation, we begin by analysing graphs relative to P2 and P5 in 2-B (Figure 7c and Figure 7d, respectively): these are the simplest pairs to discuss, since they represent pairs of MKAs forming isolated binary aggregates. Yet even in this case, apart from an expected drop in $|\cos \theta|$ fluctuations due to frustrated rotation, there seems to be little consistency between what happens within P2 and within P5. 


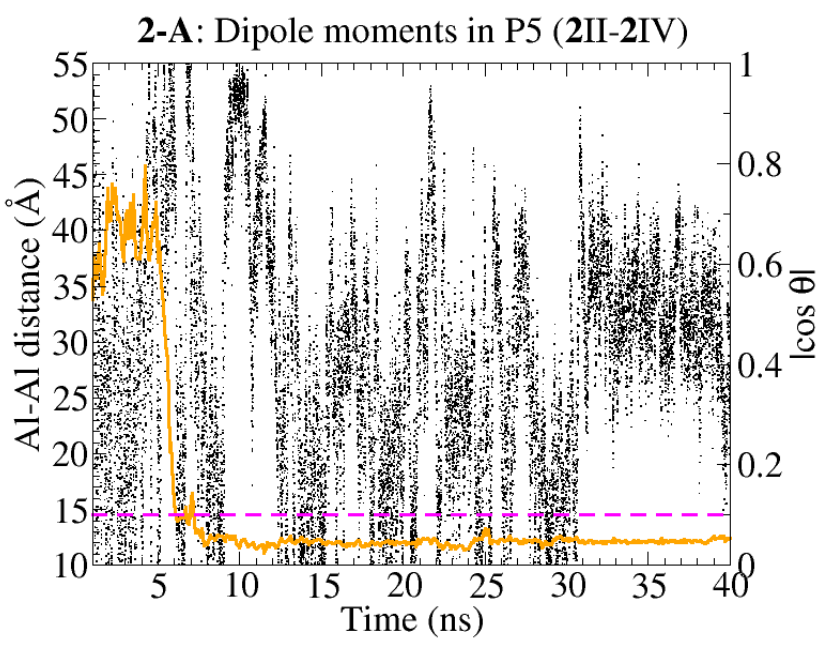

(a)

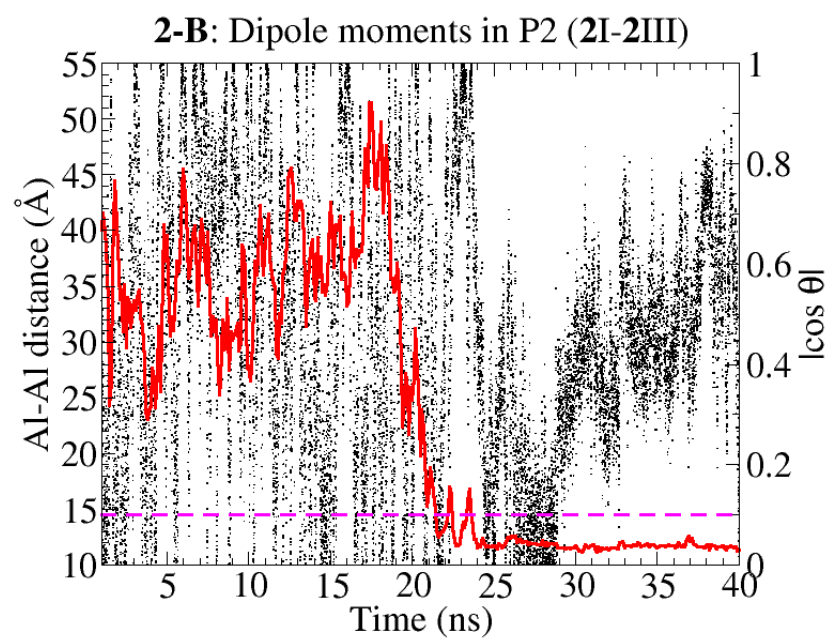

(b)
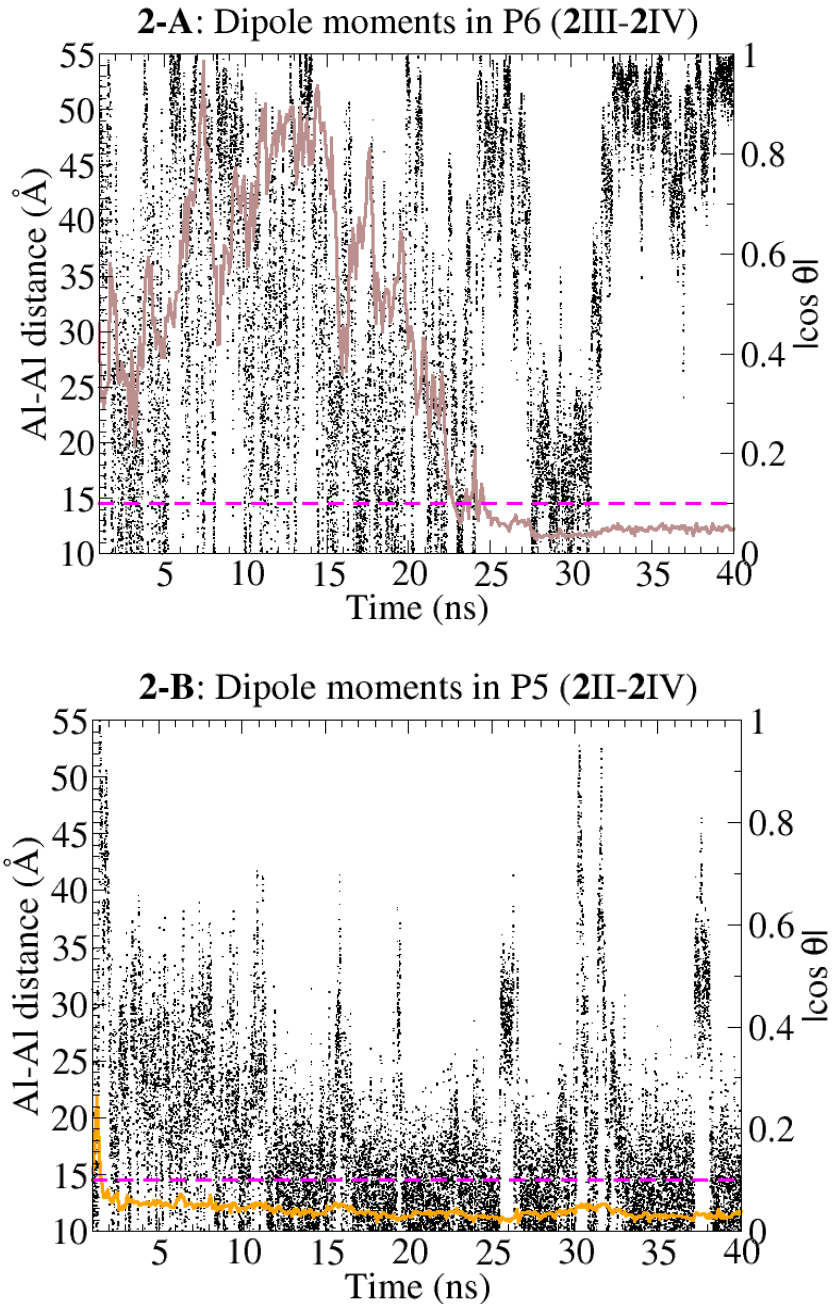

(c)

(d)

Figure 7. Graphs monitoring the relative orientation of dipole moments (black dots; quantified as $|\cos \theta|$; plotted against right-hand $y$-axes) in four selected pairs of MKAs: (a) P5 from 2-A; (b) P6 from 2-A; (c) P2 from 2-B; and (d) P5 from 2-B. These are overlaid onto the corresponding MKA-MKA distance plots from Figure 3c (2-A) and Figure 3d (2-B) (coloured lines; plotted against left-hand $y$-axes). The colour code for the distance plots is identical to the one in Figure 3; dotted magenta lines show the $14.5 \AA$ threshold below which aggregation is considered to occur (see Supporting Information). Dipole moment orientation sampled every 2 ps. $0-1$ ns (equilibration) not shown.

Upon P2's aggregation (21.5 - $23.7 \mathrm{~ns})$, dipole moments in $2 \mathrm{I}$ and $2 \mathrm{III}$ adopt a roughly parallel orientation relative to each other; by $24 \mathrm{~ns}$, however, this has rapidly flipped to roughly perpendicular $(\sim 0.07)$. After a further $5 \mathrm{~ns},|\cos \theta|$ gradually starts to rise again, fluctuating about $\sim 0.6$ by the end of the simulation (i.e. $\theta \approx 53.1^{\circ}$; although it is $67.0^{\circ}$ in the snapshot at $40 \mathrm{~ns}$ in Figure 6a).

On the other hand, $\mu$ orientations within 2-B's P5 (Figure 7d) evolve in a substantially different way upon its aggregation at $1.6 \mathrm{~ns}$. After a few instants at $\sim 1$ (parallel), $|\cos \theta|$ switches almost instantaneously to $\sim 0.35$, and then to near-perpendicular ( 0.11) at $11.5 \mathrm{~ns}$, whence, unlike within P2, and save brief exceptions, it stays as such until the end of the simulation $\left(\theta=87.1^{\circ}\right.$ at $40 \mathrm{~ns}$ in Figure $\left.6 \mathrm{~b}\right)$.

The evolution of $\mu$ orientations depicted for P5 and P6 in 2-A (Figure 7a and Figure 7b, respectively) is similarly complex and, since both pairs form part of a tertiary or quaternary aggregate for most of their aggregated lifetime, we will only comment on them in general terms. The most salient features are, once again, the parallel orientation of 2III and 2IV within P5 during the first 150 ps of its 2.5 ns-existence as a binary aggregate; and the rapid flips within both pairs' $\mu$ orientations that correspond to the transition, at $33.1 \mathrm{~ns}$, from the Y-shaped quaternary aggregate (Figure S3a) back to the bent rhombus (Figure S3b). Other than these characteristics, the relative dipole moment orientation in P5 seems to be fairly unrelated to that in P6, probably also influenced by their different positions in the 2II-2III-2IV aggregate, both with respect to each other and with respect to 2I. 


\section{Assessing aggregation in the Fictitious Anion 3}

The results just presented seem to rule out a direct involvement of $\mu$ in the aggregation of 2 . We thus set out to investigate the alternative hypothesis outlined in the Introduction, whereby it is the higher charge on $\mathbf{2}$ alone that, at the simulated concentration, that is sufficient to drive aggregation by favourably altering countercation distribution. In fact, along the lines of what reported by Chaumont and Wipff, ${ }^{68,69}$ we still believe that, even if $\mu$ is not involved, countercations must be implicated in some way: otherwise, the fact that aggregation occurs with -9 but not with -5 would remain blatantly illogical. This suspicion is furthermore reinforced by the fact that, in Figure 4-Figure 6, $\mathrm{O} \cdots \mathrm{Li}^{+} \cdots \mathrm{O}$ bridges are always present in the illustrated aggregates (replacing hydration water; see Supporting Information).

It is at this point that we introduce comparative MD simulations of the fictitious PKA anion 3: $\mathbf{3}$ is deemed an ideal choice to test this second hypothesis, as it can basically be considered as " $\mathbf{1}$ with charge $-\mathbf{9}$ and $\mathbf{2}$ without a dipole moment". In other words, its structure, composition, symmetry, and lack of $\mu$ are identical to those of $\mathbf{1}$, but its overall charge and point charges mimic those on $\mathbf{2}$. If aggregation were indeed reproduced in $\mathbf{3}$ too, this would therefore definitely exclude a role of $\mu$.
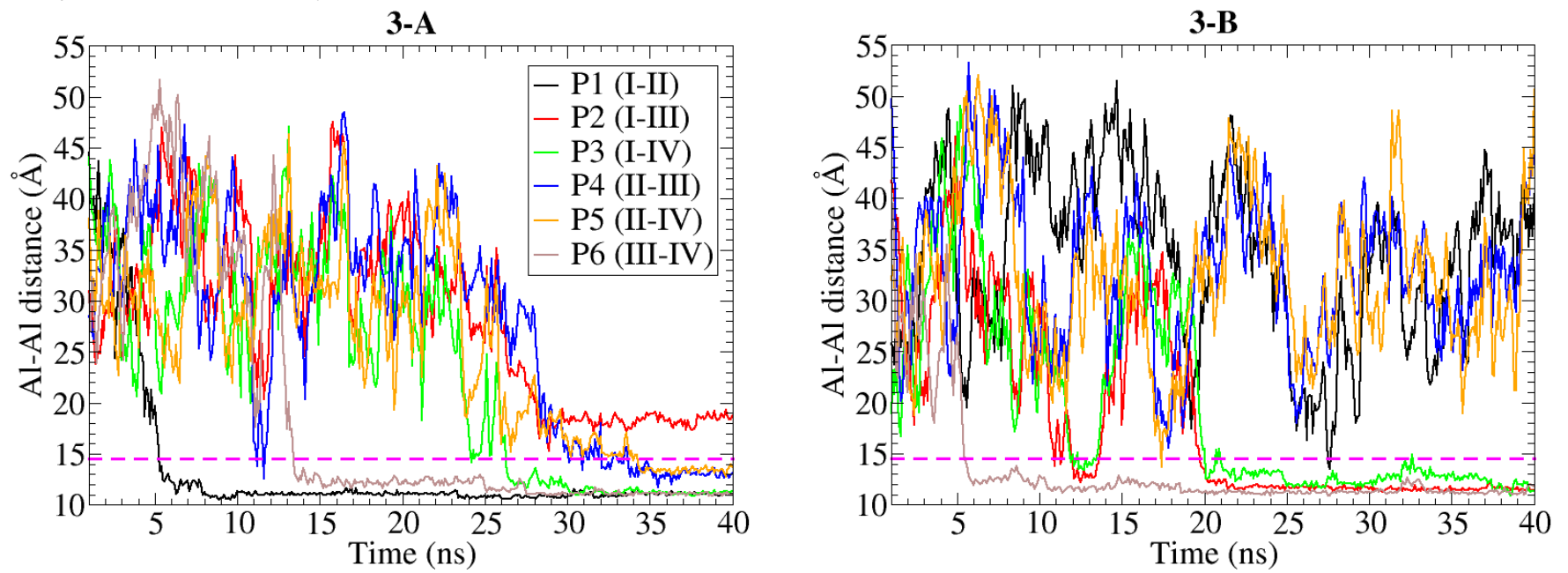

(a)

(b)

Figure 8. Evolution of Keggin-Keggin distances in independent systems (a) 3-A; and (b) 3-B; during the last 39 ns of MD simulation (Stage III; 1 $-40 \mathrm{~ns}$ ), and as measured from each Keggin's aluminium centre. The four specimens of $\mathbf{3}$ present in each system (identifiable as 3I-3IV), give rise in each case to six individual Keggin-Keggin pairs, numbered P1-P6; hence six aluminium-aluminium distances ( $c f$. universal colour code and nomenclature in (a)). Dotted magenta lines denote the $14.5 \AA$ threshold below which aggregation is considered to occur (see Supporting Information). Distances are sampled every 100 ps. $0-1$ ns (equilibration) not shown.

With this in mind, we return to simulate two independently prepared $\sim 0.026 \mathrm{M}$ solutions of $\mathrm{Li}_{9} \mathbf{3}$ (3-A and 3-B), set up in an identical way to $\mathbf{1 - A}, \mathbf{1 - B}, \mathbf{2 - A}$, and $\mathbf{2 - \mathbf { B }}$, to test whether or not $\mathbf{3}$ is indeed able to form aggregates. As in systems featuring $\mathbf{1}$ and $\mathbf{2}$, aggregation in $\mathbf{3}$ is assessed by individually monitoring the six Keggin-Keggin distances in 3A and 3-B throughout the production stage, at $100 \mathrm{ps}$ intervals, and is considered to occur when at least one of these falls below the usual threshold of $14.5 \AA$. These distance plots are shown in Figure 8, which uses the same colour code as Figure 3 to refer to the six pairs P1 (3I-3II) to P6 (3III-3IV) in both 3-A and 3-B.

It is clear from both distance plots in Figure 8 that the aggregative behaviour of $\mathbf{3}$ in $\mathbf{3}-\mathbf{A}$ and $\mathbf{3}-\mathbf{B}$ is much more similar to that of $\mathbf{2}$ (Figure $3 \mathrm{~b}$ and $\mathrm{c}$ ) than to that of $\mathbf{1}$ (Figure $3 \mathrm{a}$ and $\mathrm{b}$ ). Like in the former case, as confirmed by visual inspection, MD simulations of both 3-A and 3-B lead to the formation of stable aggregates, which look set to survive past the end of the production stage. 


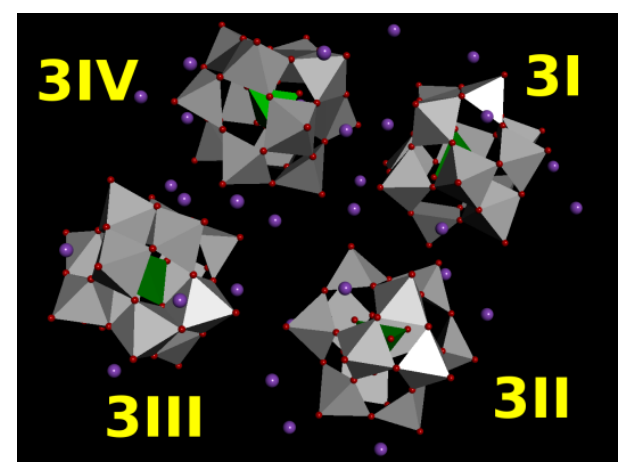

Figure 9. Snapshot at $40 \mathrm{~ns}$ of the quaternary aggregate of the fictitious PKA 3 arising in 3-A during the MD production stage. Key: same as Figure 4, with water molecules and distal $\mathrm{Li}^{+}$omitted for clarity.

Keggin-Keggin distance plots for 3-A (Figure 8a) show that P2 forms the first binary aggregate already at $5.2 \mathrm{~ns}$. Between $11.2 \mathrm{~ns}$ and $11.8 \mathrm{~ns}, 3 \mathrm{III}$ unsuccessfully attempts to join this to form a linear ternary aggregate ( $c f$. plot for P4); shortly afterwards however, at $13.4 \mathrm{~ns}$, it instead joins 3IV to form an independent binary aggregate (cf. plot for P6). The two binary aggregates survive separately for about $10.7 \mathrm{~ns}$, after which, between $24.2 \mathrm{~ns}$ and $26.3 \mathrm{~ns}$, they approach each other and fuse between 3I and 3IV ( $c f$. P3), to become a quasi-linear quaternary aggregate. Between $30 \mathrm{~ns}$ and 35 ns, this finally bends into a rhombus ( $c f . \mathrm{P} 4$ and $\mathrm{P} 5)$, which it remains as until the end of the simulation, as illustrated in Figure 9.

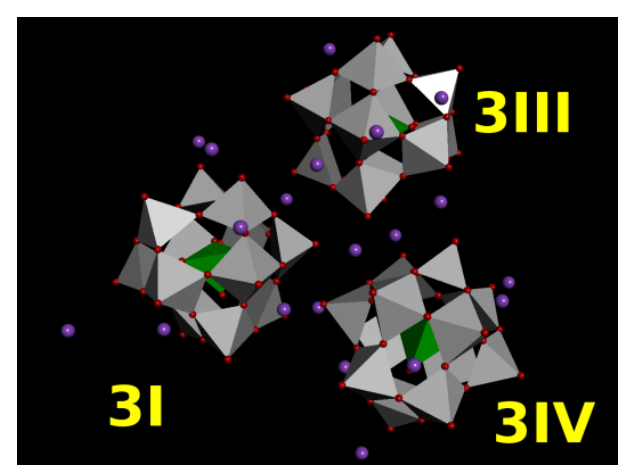

Figure 10. Snapshot at $40 \mathrm{~ns}$ of the ternary aggregate formed by the fictitious PKAs 3I, 3III, and 3IV, arising in 3-B during the MD production stage. Key: same as Figure 4, with water molecules and distal $\mathrm{Li}^{+}$omitted for clarity.

In 3B (Figure 8b), we observe a very similar situation: the first binary aggregate is formed by P6 at 5.5 ns. Until about $20 \mathrm{~ns}$, this exists on its own, apart from three brief stints as: a linear tertiary aggregate, when 3I attempts to approach it at 3III (10.7-11.4 ns; $c f$. P2); a triangular ternary aggregate, when 3I returns between 3III and 3IV (11.9-13.6 ns; $c f . \mathrm{P} 2$ and $\mathrm{P} 3$ ); and another triangular ternary aggregate when 3II briefly attempts to do the same (17.5 ns; $c f . \mathrm{P} 4$ and P5). At $20 \mathrm{~ns}$, finally, 3I approaches 3III and 3IV for the third time: this time, a stable triangular ternary aggregate is formed, which 3II unsuccessfully attempts to join at 3I (27.6-27.7 ns; $c f$. P1), and which survives until the end of the simulation (Figure 10).

\section{$\mathrm{Li}^{+}$Distribution Around 1, 2 and 3}

MD results presented above for 3-A and 3-B provide strong evidence that Keggin anion aggregation does indeed occur even in the absence of $\mu$. It is then all the more evident that, since $\mathbf{1}$ and $\mathbf{3}$ only differ in their charge and in nothing else, the key factor behind aggregation must be the higher charge in $\mathbf{3}$ (and 2), as per our second hypothesis; not 2's $\mu$.

On the grounds of simple electrostatics, it is easy to see that the -9 charge on $\mathbf{2}$ and $\mathbf{3}$ cannot act alone to drive aggregation: it should act, on the other hand, via a mechanism that necessarily also relies on the positively charged countercations, and one that the -5 charge on 1 should not be able to initiate. A likely involvement of the cations is in fact equally suggested by all of the previous aggregate snapshots: in Figure S3, Figure 5, Figure 6, Figure 9, and Figure 10, all Keggin aggregates formed by $\mathbf{2}$ and $\mathbf{3}$ are seen in association with copious amounts $\mathrm{Lf}^{+}$; on the other hand, in the snapshot of the transient aggregate arising in 1-B (Figure 4), the presence of $\mathrm{O}^{\cdots} \mathrm{Li}^{+}$contacts is noticeably more scant. 
To more formally probe the existence of such a mechanism, we decide to carry out a full-scale analysis, across all six of our simulated systems, of how many $\mathrm{Li}^{+}$cations are free in solution at any one time during MD production, and how many are instead associated with one or more Keggin anion 'neighbours'. We then complete this analysis by calculating, in each case, general statistics for the entire production stage, broken down by individual Keggin anions, whether aggregated or not.

The analysis is carried out using an $a d$ hoc in-house program, which relies on $\mathrm{Li}^{+}$-Keggin distances as measured by the appropriate GROMACS utility. ${ }^{81,82}$ The arbitrary threshold below which we consider a hydrated $\mathrm{Li}^{+}$and a Keggin anion to be 'neighbours' (i.e. noncovalently associated) is set at $11.44 \AA$ as measured from the Keggin's aluminium centre. Derivation of this threshold is outlined as Supporting Information, as are our program's mode of action and parameters, and a more detailed description of how $\mathrm{Li}^{+}$hydration evolves upon recruitment by Keggin anions.

In the six panels of Figure 11 we illustrate, for each of the six systems 1-A, 1-B, 2-A, 2-B, 3-A, and 3-B, and at every picosecond of the $39 \mathrm{~ns}$ production stage, the exact proportion of $\mathrm{Li}^{+}$cations that are either isolated in solution (cyan); or associated with one (red); two (green); three (dark blue); or four Keggin anion neighbours (orange). All of these cases are mutually exclusive.

\begin{tabular}{|c|c|c|c|c|c|}
\hline & free $\mathrm{Li}^{+}$ & on $\mathbf{I}^{a}$ & on $\mathbf{I I}^{a}$ & on III $^{a}$ & on $\mathbf{I} \mathbf{V}^{a}$ \\
\hline 1-A & 11.36 & 2.30 & 2.25 & 2.13 & 2.11 \\
\hline 1-B & 11.37 & 2.35 & 2.00 & 2.21 & 2.19 \\
\hline 2-A & 2.68 & 9.35 & 9.90 & 8.77 & 12.21 \\
\hline 2-B & 3.10 & 9.62 & 11.16 & 9.51 & 10.72 \\
\hline 3-A & 3.57 & 10.87 & 10.40 & 9.74 & 10.46 \\
\hline 3-B & 3.93 & 8.55 & 7.54 & 10.14 & 9.47 \\
\hline
\end{tabular}

Table 1. Overall averages of the $\mathrm{Li}^{+}$cations found in our six simulated systems to be either: free in solution; or associated to Keggin anion I (1I, 2I, 3I), II, III, and/or IV. Statistics are elaborated after the counts in Figure 11.

We should also note that "number of Keggin anion neighbours" is not synonymous with "aggregate size": for example, a $\mathrm{Li}^{+}$with a neighbour count of 3 could be part of a triangular ternary aggregate just as much as it could be part of a Y-shaped quaternary aggregate ( $c f$. the one occurring at $30 \mathrm{~ns}$ in $\mathbf{2 - A}$ ), in which the 'fourth' Keggin is not close enough to be detected.

(a)

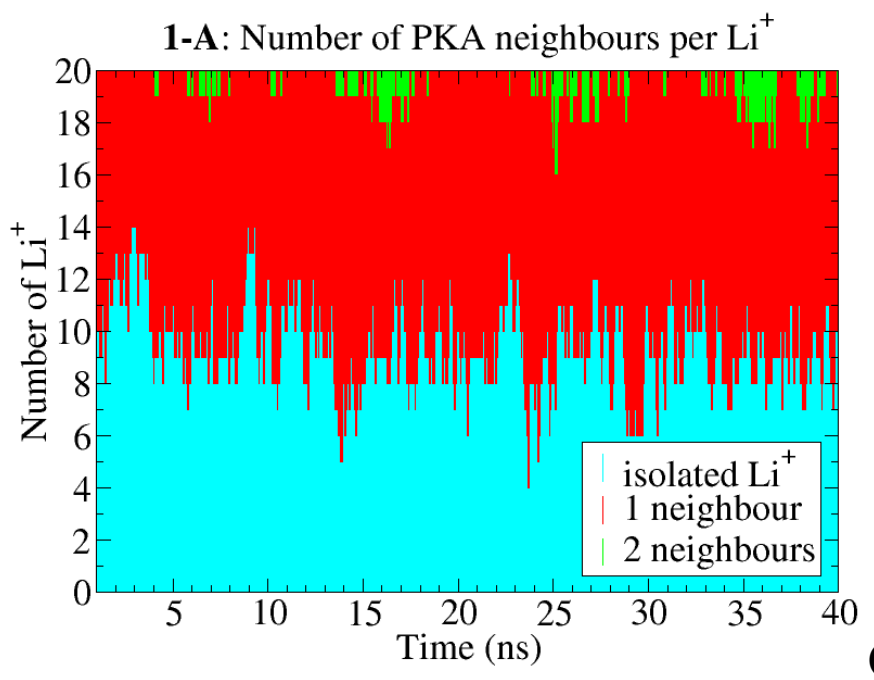

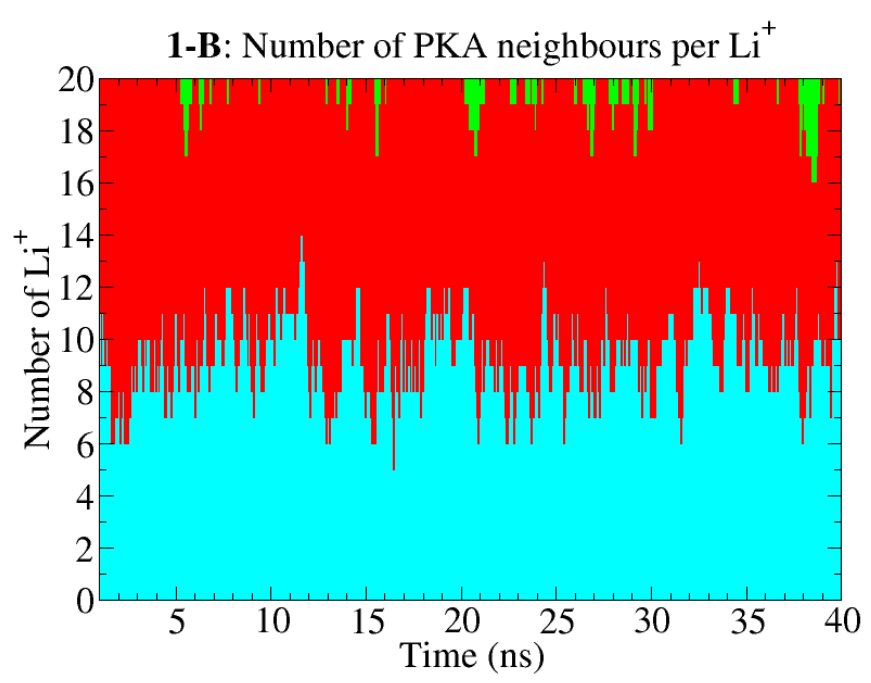


2-A: Number of MKA neighbours per $\mathrm{Li}^{+}$

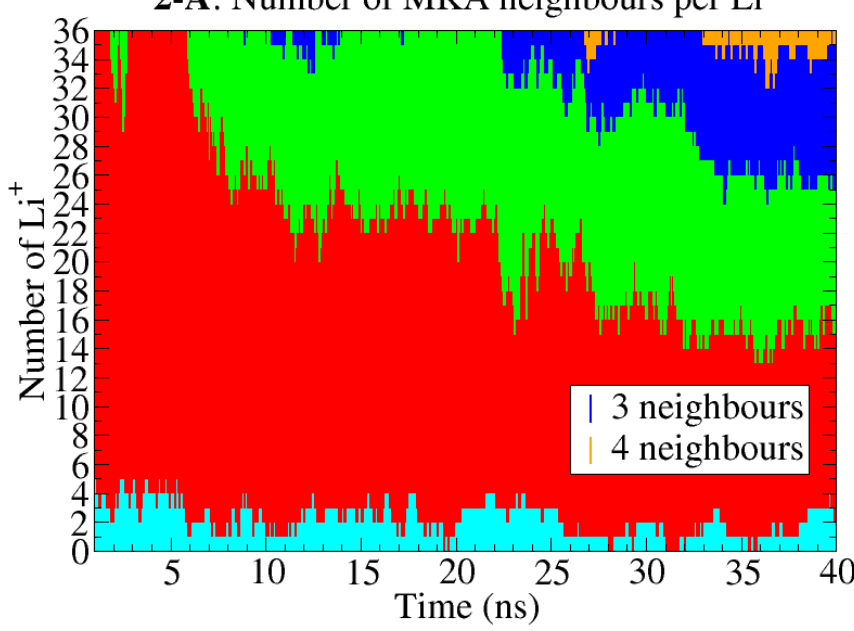

(c)

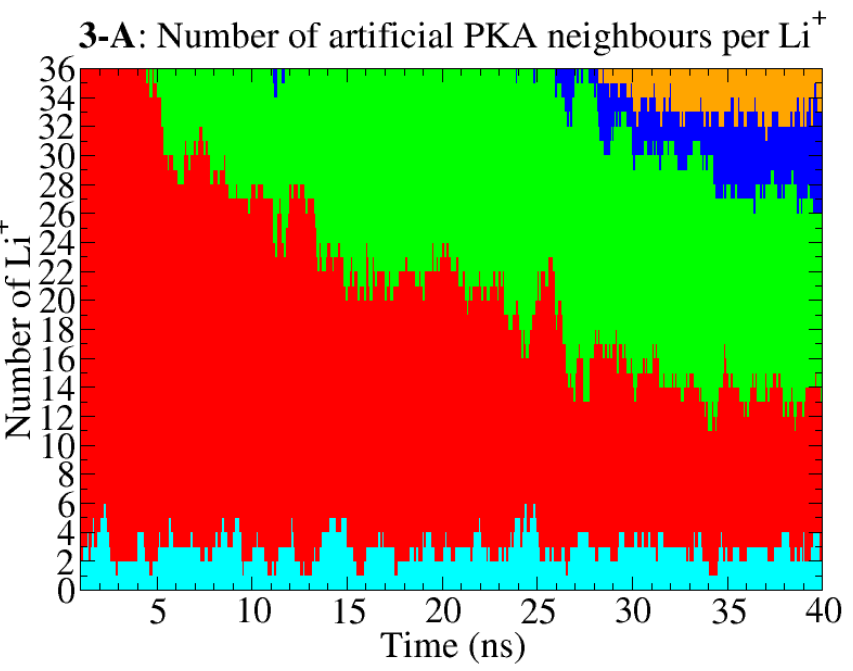

(d)

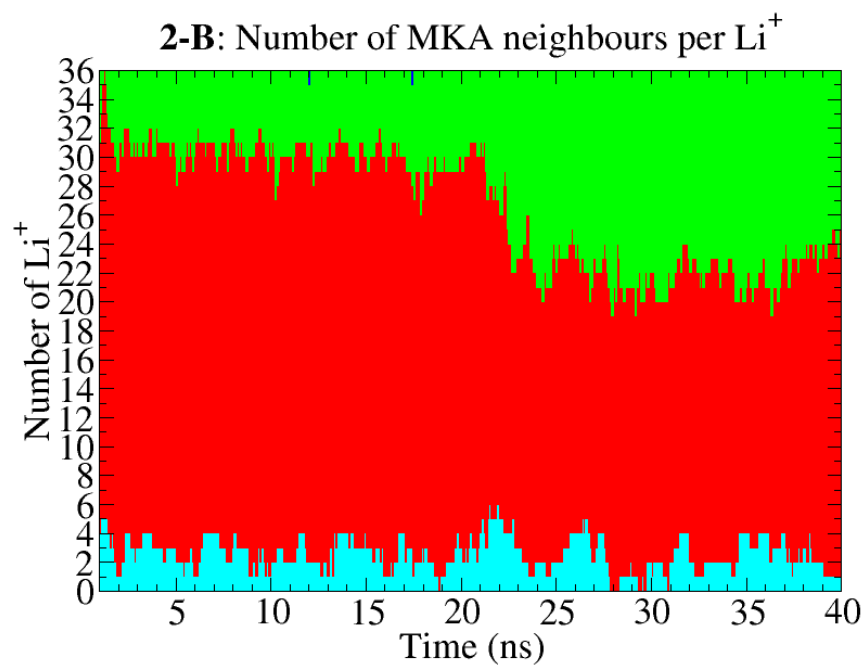

3-B: Number of artificial PKA neighbours per $\mathrm{Li}^{+}$

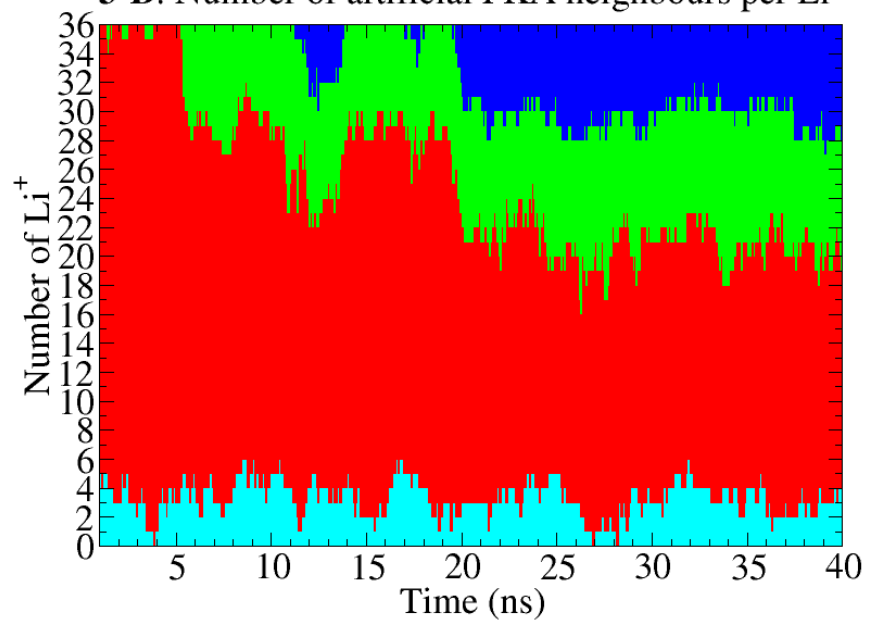

Figure 11. Proportion of lithium cations, sampled at every picosecond of the 39 ns production stage, that are either isolated in solution (cyan area); or associated with one Keggin anion neighbour (red); with 2 (green); with 3 (dark blue); or with 4 (orange). The analysis is carried out on (a) 1-A; (a) 1-B; (a) 2-A; (a) 2-B; (a) 3-A; and (a) 3-B alike. A lithium cation is considered to be a Keggin anion's 'neighbour' when it is less than $11.44 \AA$ away from its aluminium centre.

Overall statistics for the entire production stage, broken down by isolated lithia and individual Keggin anions (1I 1IV, 2I - 2IV, and 3I-3IV) — regardless of aggregation-are instead tabulated in Table 1.

From slightly different perspectives, both Figure 11 and Table 1 confirm that the behaviour of lithium in aqueous solutions of $\mathrm{Li}_{5} \mathbf{1}$ is significantly different from its behaviour in solutions of $\mathrm{Li}_{9} \mathbf{2}$ and $\mathrm{Li}_{9} \mathbf{3}$; and that in the latter two, it is in fact very similar, despite $\mathbf{2}$ having a $\mu$ and $\mathbf{3}$ not.

Figure $11 \mathrm{a}$ and $\mathrm{b}$ show that, in both $\mathbf{1 - A}$ and $\mathbf{1 - B}$, there is a considerable predominance of $\mathrm{Li}^{+}$cations (cyan) that stay free in solution for the entire production stage; Table 1 confirms this, showing that, on average, 11.36 lithia out of 20 remain non-associated in $\mathbf{1 - A}$, and 11.37 remain non-associated in 1-B. In accordance with the almost complete lack of aggregation, the vast majority of non-isolated lithia only features one Keggin anion neighbour. Episodes of lithia with two neighbours are scarce and transient: the most conspicuous (1-B at $38.1-38.4 \mathrm{~ns}$ ) corresponds to the longestlived aggregate ( $c f$. Figure 3a, Figure 3b, and Figure 4). It should also be mentioned that, as best exemplified by Figure $11 \mathrm{a}$, the $11.44 \AA$ threshold may well lead to the detection of two Keggin neighbours on a lithium even if the two are slightly farther apart than the $14.5 \AA$ required to be considered as an aggregate.

Moreover, Table 1 indicates that, despite the overall charge of -5 on each instance of 1 , the four PKAs 1I - 1IV are only able to recruit, on average, between 2.00 and 2.35 lithium partners.

In the four systems featuring $\mathrm{Li}_{9} 2$ and $\mathrm{Li}_{9} 3$, the situation is radically different. Compared to Figure $11 \mathrm{a}$ and $\mathrm{b}$, the cyan area in Figure 11c-f is almost wiped out, indicating that the proportion of lithium cations free in solution is very low in all four systems (an average of 2.68-3.93 out of 36 according to Table 1). Furthermore, the number of isolated lithia seems to be unaffected by presence, size, or number of aggregates, as indicated by the horizontality of the redcyan boundary, right from the earliest stages of production. 
Expectedly, the appearance of larger Keggin neighbour counts in the later stages of MD production roughly reflects the appearance of larger or multiple aggregates resulting from Figure 3c, Figure 3d, and Figure 8 (despite the two quantities not being synonymous). For example, in $\mathbf{2 - A}$ and $\mathbf{3 - A}$, the formation of rhomboidal quaternary aggregates is duly reflected by the appearance of lithia with four neighbours in Figure 11c and e (whereas the Y-shaped aggregate in 2-A goes undetected).

Unlike 1I - 1IV, which are able to recruit less lithium cations than dictated by their -5 charge, Table 1 values crucially show that the situation with $2 \mathrm{I}-2 \mathrm{IV}$ and $3 \mathrm{I}-3 \mathrm{IV}$ is quite the opposite: the number of lithia captured by each anion is almost always higher than 9 (ranging from 9.35 on $2 \mathrm{I}$ in $\mathbf{2 - A}$ to 12.21 on $2 \mathrm{IV}$ in $\mathbf{2 - A}$ ). The three exceptions (7.54, 8.55, and 8.77), observed in 3-B and 2-A respectively, remain in any case quite close to 9.

\section{Discussion}

\section{Plenary are solitary}

Both visual inspection and the distance plots in Figure 3 amply confirm the very different behaviour of the PKA salt $\mathrm{Li}_{5} \mathbf{1}$ and the MKA salt $\mathrm{Li}_{9} \mathbf{2}$ during the production stage of their respective MD simulations. These differences are also encouragingly replicated across independent systems $\mathbf{A}$ and $\mathbf{B}$ both in the case of $\mathrm{Li}_{5} \mathbf{1}$ and in the case of $\operatorname{Li}_{9} \mathbf{2}$.

Our simulations manage to produce stable lacunary Keggin anion aggregation in systems featuring 2 (2-A and 2B), with the formation of binary, tertiary, and quaternary aggregates (Figure 5 and Figure 6) surviving right up to the end of all simulations. On the other hand, aggregation in systems featuring $\mathbf{1}$ (1-A and 1-B) is almost inexistent, with aggregates only surviving for a few picoseconds (Figure 4): this particular observation is completely in line with the in silico findings previously reported by Chaumont and Wipff ${ }^{69}$ who, in their simulations of $\mathrm{Li}_{5} \mathbf{1}$ and other PKA salts at various concentrations, also only observe transient aggregation. Similarly short lifetimes are also reported by Bera et al. from their simulations of PKA in acid medium. ${ }^{70}$

\section{No dipole, no party?}

As per the first of the two hypotheses provided in the introduction, our priority is to investigate whether 2's unique dipole moment $\mu$ could be the determining factor in its prompt aggregation. However, when in Figure 7 we compare the relative orientation of $\mu$ in four selected pairs of 2, in both $\mathbf{2 - A}$ and 2-B, it is impossible to detect any concrete change in $\mu$ alignment upon aggregation, apart from an understandable drop in $\mu$ fluctuations due to rotational hindrance. Influence of $\mu$ on aggregation should therefore be definitely ruled out.

From a physical point of view, such clear lack of influence could be justifiable by invoking Keesom's energy $U_{\text {dip }}{ }^{87}$ which refers to the interaction between two freely rotating spherical molecules with permanent dipole moments (i.e. the situation of LKAs prior to aggregation). The equation for $U_{\text {dip }}$ for two molecules with identical $\mu$ at distance $r$ and at temperature $T$ is

$$
U_{\text {dip }}=-\frac{2}{3 k_{\mathrm{B}} T}\left(\frac{\mu^{2}}{4 \pi \varepsilon_{0} \varepsilon}\right)^{2} \frac{1}{r^{-6}}
$$

where $k_{\mathrm{B}}$ is Boltzmann's constant, $\varepsilon$ is the dielectric constant of the (in this case) water, and $\varepsilon_{0}$ is the vacuum permittivity constant. Not only does $U_{\text {dip }}$ in this form not depend on relative orientation of $\mu$, but one can see that, even at $14.5 \AA$ (closer than which a pair of LKAs cannot physically be), the $r^{-6}$ dependence of $U_{\text {dip }}$ brings it to near-zero values, whereby, even with the $\mu$ of $\sim 12$ D present on $\mathbf{2}$, two molecules of 2 would not be able to 'feel' each other. 


\section{A cationic glue}

After ruling out any involvement of $\mu$, the introduction of MD simulations of $\mathrm{Li}_{9} \mathbf{3}$ solutions (in 3-A and 3-B) is viewed as a sort of acid test to see whether, indeed, it is simply the higher charge, rather than $\mu$, that plays a role in aggregation. Thus, the unequivocal formation of aggregates in 3-A and 3-B (Figure 9 and Figure 10), recognisable in the distance plots in Figure 8, strongly implies that aggregates in 2-A and 2-B too only form because of 2's -9 charge.

Turning once again to the 2013 studies by Chaumont and Wipff, ${ }^{69}$ one can see that, although the authors only worked with PKAs and therefore only saw transient aggregation, they did nevertheless report that aggregation occurred more frequently in $\left[\mathrm{AlW}_{12} \mathrm{O}_{40}\right]^{5-}$ solutions than it did in those with the less charged $\left[\mathrm{SiW}_{12} \mathrm{O}_{40}\right]^{4-}$ and $\left[\mathrm{PW}_{12} \mathrm{O}_{40}\right]^{3-}$. Even if it concerns species with much lower charges, this observation is still very much in line with our own, and somewhat reinforces our hypothesis that, all else being equal in our particular study, the -9 charge on $\left[\mathrm{AlW}_{11} \mathrm{O}_{39}\right]^{9-}$ is the main factor driving its aggregation.

We have noted several times, by now, that in order to drive aggregation, the higher negative charge on 2 must be working in co-operation with the lithium countercations to some extent. In this respect, the relevance of contacts between PKAs and alkali metal countercations was also studied in detail by Chaumont and Wipff, ${ }^{68,69}$ and, to a lesser extent, by Leroy et al.: ${ }^{66}$ all simulations found that aggregate formation, no matter how transient, inexorably depends on the nature of the countercation too, ${ }^{68,69}$ with the combination of $\left[\mathrm{AlW}_{12} \mathrm{O}_{40}\right]^{5-}$ and $\mathrm{Li}^{+}$incidentally giving the most favourable results thanks to the exceptional energetic stability enjoyed by the $\mathrm{Li}^{+}-\left[\mathrm{AlW}_{12} \mathrm{O}_{40}\right]^{5-}$ ion pair. ${ }^{66,69}$ In any case, countercations were reported to often act as an outright "electrostatic glue", promoting the formation of Keggin anion oligomers.

Reproduction in our MD simulations of such "cationic glue" effect is exactly what seems emerge from the aggregate snapshots in Figure 4, Figure 6, Figure 9, and Figure 10, wherein a varying number of dehydrated or partlydehydrated lithium cations is always seen to be interspersed between aggregating Keggin anions, forming $\mathrm{O}^{\cdots} \mathrm{Li}^{+} \cdots \mathrm{O}$ contacts.

From the $\mathrm{Li}^{+}$counts presented in Figure 11 and Table 1, we are also able to see that, thanks to their higher charge, 2 and $\mathbf{3}$ are able to take much better advantage of this lithium glue: even when not aggregated, each of these anions is able to recruit a relatively large number of $\mathrm{Li}^{+}$companions ( $>9$ on average), which we believe greatly improves their chances to form aggregates. By contrast, the lower charge on $\mathbf{1}$ only allows it to recruit a limited number of countercations, with a large excess remaining free in solution: this inevitably jeopardises its ability to aggregate.

Ultimately, another element that strongly supports the importance of charge and irrelevance of $\mu$ is the aggregation into supramolecular vescicles that has been experimentally observed in solution for much larger, and much more negatively charged POMs, even if lacking a $\mu^{43,45-48,88}$ ( $c f$. Introduction). Our results also lead us to believe that, were simulations repeated with the structural isomers of $\mathbf{1}$ and $2 \beta-\left[\mathrm{AlW}_{12} \mathrm{O}_{40}\right]^{5-}$ and $\beta_{3}-\left[\mathrm{AlW}_{11} \mathrm{O}_{39}\right]^{9-}$, 89 their outcome would be unchanged.

\section{Conclusions and Summary}

In this publication, we have presented a series of large-scale molecular dynamics simulations (MD), 39 ns in length, featuring aqueous lithium salts of: the plenary Keggin anion $\left[\mathrm{AlW}_{12} \mathrm{O}_{40}\right]^{5-}$; its lacunary counterpart $\left[\mathrm{AlW}_{11} \mathrm{O}_{39}\right]^{9-}$; and the fictitious plenary Keggin anion $\left[\mathrm{AlW}_{12} \mathrm{O}_{40}\right]^{9-}$. To the best of our knowledge, simulation of $\left[\mathrm{AlW}_{11} \mathrm{O}_{39}\right]^{9-}$ and $\left[\mathrm{AlW}_{12} \mathrm{O}_{40}\right]^{9-}$ is unprecedented.

Our simulations led to the formation of stable, long-lived Keggin anion aggregates in solutions of $\mathrm{Li}_{9} \mathrm{AlW}_{11} \mathrm{O}_{39}$. On the other hand, despite the lower negative charge on $\left[\mathrm{AlW}_{12} \mathrm{O}_{40}\right]^{5-}$, aggregation observed in solutions of $\mathrm{Li}_{5} \mathrm{AlW}_{12} \mathrm{O}_{40}$ was transient at best, when present at all.

We thus set out to investigate the reasons behind this fascinating difference in properties. The first possible cause we investigated is the strong dipole moment present in $\left[\mathrm{AlW}_{11} \mathrm{O}_{39}\right]^{9-}$ but absent in $\left[\mathrm{AlW}_{12} \mathrm{O}_{40}\right]^{5-}$. However, analysis of relative dipole moment orientation in pairs of aggregated $\left[\mathrm{AlW}_{11} \mathrm{O}_{39}\right]^{9-}$ did not reveal any regular alignment patterns: the possibility of dipole moment being a decisive factor in aggregation was therefore discarded.

Suspecting, then, that the higher charge on $\left[\mathrm{AlW}_{11} \mathrm{O}_{39}\right]^{9-}$ alone might behind its greater propensity to aggregate (in necessary co-operation with the lithium countercations), we introduced MD simulations of $\mathrm{Li}_{9} \mathrm{AlW}_{12} \mathrm{O}_{40}$, with the precise intention of studying a fictitious Keggin anion that featured the same high negative charge as $\left[\mathrm{AlW}_{11} \mathrm{O}_{39}\right]^{9-}$, but 
that, like $\left[\mathrm{AlW}_{12} \mathrm{O}_{40}\right]^{5-}$, lacked a permanent dipole moment. In line with this second hypothesis, despite the lack of dipole moment, solutions of $\mathrm{Li}_{9} \mathrm{AlW}_{12} \mathrm{O}_{40}$ were equally seen to give rise to stable aggregates with identical characteristics to those observed in $\mathrm{Li}_{9} \mathrm{AlW}_{11} \mathrm{O}_{39}$. This confirmed the important contribution to aggregation that the higher negative charge on the lacunary $\left[\mathrm{AlW}_{11} \mathrm{O}_{39}\right]^{9-}$ is able to provide at the tested concentration of $0.026 \mathrm{M}$.

Furthermore, in confirmation of countercations' key role in mediating aggregation of the more negatively charged $\left[\mathrm{AlW}_{11} \mathrm{O}_{39}\right]^{9-}$ and $\left[\mathrm{AlW}_{12} \mathrm{O}_{40}\right]^{9-}$, we find that, throughout their respective MD simulations, even when not aggregated, both of these anions are able to recruit an average of 9.90 lithium cations each: this is evidently enough to annul the -9 negative charge, and "electrostatically glue" the anions together. On the other hand, $\left[\mathrm{AlW}_{12} \mathrm{O}_{40}\right]^{5-}$ are only able to recruit an average of 2.19 cations each, with a large excess remaining free in solution: the "electrostatic glue" effect is not replicated in this case, and this is why aggregation at low concentrations is not observed in our simulations.

With our work, we hope to have once again highlighted the extra benefits that classical MD simulations can provide when seeking to understand the all-important dynamic properties of Keggin anions (and other polyoxometalates) in solution. Simulations featured here are run at particularly low concentrations, and with no additional electrolytes; yet they still indicate the creation of very long lived (nanoseconds scale) aggregates in the case of lacunary Keggins. We are convinced that the results presented here pave the way for further experimental studies on those highly charged species.

Supporting Information. Forcefield equations, parameters, and other details not covered in the main text. Characteristics and setup of individual MD simulations. Post-MD analysis (quantification of Keggin anion aggregation; supplementary illustrations of the aggregates in $\mathbf{2 - A}$; calculation of dipole moment orientation; quantification of $\mathrm{Li}^{+}-$ Keggin anion association). Hydration of $\mathrm{Li}^{+}$cations in the vicinity of aggregates.

\section{Acknowledgements}

The authors wish to acknowledge the financial support of the European Union (Marie Curie Actions COFUND; Grant: 291787-ICIQ-IPMP), of the Spanish Ministry of the Economy and Competitiveness (Grant: CTQ2014-52824-R and the Severo Ochoa Excellence Accreditation SEV-2013-0319), and of the ICIQ Foundation and of the Generalitat de Catalunya (2014SGR409).

\section{References}

1. Berzelius, J. J. Beitrag zur näheren Kenntniss des Molybdäns. Ann. Phys. Chem. 1826, 82, $369-392$.

2. Keggin, J. F. Structure of the Molecule of 12-Phosphotungstic Acid. Nature 1933, 131, $908-909$.

3. Baker, L. C. W.; Baker, V. S.; Eriks, K.; Pope, M. T.; Orville, M. S.; Rollins, W.; Fang, J. H.; Koh, L. L. A New General Structural Category of Heteropolyelectrolytes. Unusual Magnetic and Thermal Contraction Phenomena. J. Am. Chem. Soc. 1966, 88, 2329-2331.

4. Cronin, L.; Müller, A. From Serendipity to Design of Polyoxometalates at the Nanoscale, Aesthetic Beauty and Applications. Chem. Soc. Rev. 2012, 41, 7333-7334.

5. Song, Y.-F.; Tsunashima, R. Recent Advances on Polyoxometalate-Based Molecular and Composite Materials. Chem. Soc. Rev. 2012, 41, 7384-7402.

6. Wang, S.-S.; Yang, G.-Y. Recent Advances in Polyoxometalate-Catalyzed Reactions. Chem. Rev. 2015, 115, 4893-4962.

7. Clemente-Juan, J. M.; Coronado, E.; Gaita-Arino, A. Magnetic Polyoxometalates: from Molecular Magnetism to Molecular Spintronics and Quantum Computing. Chem. Soc. Rev. 2012, 41, 7464-7478.

8. Pang, H.; Gomez-Garcia, C. J.; Peng, J.; Ma, H.; Zhang, C.; Wu, Q. Monolacunary Keggin Polyoxometalates Connected to Ten 4d or 4f Metal Atoms. Dalton Trans. 2013, 42, 16596-16601.

9. Ammam, M. Polyoxometalates: Formation, Structures, Principal Properties, Main Deposition Methods and Application in Sensing. J. Mater. Chem. A 2013, 1, 6291-6312.

10. Lee, S.-Y.; Fiene, A.; Li, W.; Hanck, T.; Brylev, K. A.; Fedorov, V. E.; Lecka, J.; Haider, A.; Pietzsch, H.-J.; Zimmermann, H., et al. Polyoxometalates-Potent and Selective Ecto-Nucleotidase Inhibitors. Biochem. Pharmacol. (Amsterdam, Neth.) 2015, 93, 171-181. 
11. Stephan, H.; Kubeil, M.; Emmerling, F.; Müller, C. E. Polyoxometalates as Versatile Enzyme Inhibitors. Eur. J. Inorg. Chem. 2013, 2013, 1585-1594.

12. Matt, B.; Xiang, X.; Kaledin, A. L.; Han, N.; Moussa, J.; Amouri, H.; Alves, S.; Hill, C. L.; Lian, T.; Musaev, D. G., et al. Long Lived Charge Separation in Iridium(III)-Photosensitized Polyoxometalates: Synthesis, Photophysical and Computational Studies of Organometallic-Redox Tunable Oxide Assemblies. Chem. Sci. 2013, 4, 1737-1745.

13. Rinfray, C.; Renaudineau, S.; Izzet, G.; Proust, A. A Covalent Polyoxomolybdate-Based Hybrid with Remarkable Electron Reservoir Properties. Chem. Commun. 2014, 50, 8575-8577.

14. Proust, A.; Matt, B.; Villanneau, R.; Guillemot, G.; Gouzerh, P.; Izzet, G. Functionalization and PostFunctionalization: A Step Towards Polyoxometalate-Based Materials. Chem. Soc. Rev. 2012, 41, 7605-7622.

15. Proust, A.; Thouvenot, R.; Gouzerh, P. Functionalization of Polyoxometalates: Towards Advanced Applications in Catalysis and Materials Science. Chem. Commun. 2008, 1837-1852.

16. Dolbecq, A.; Dumas, E.; Mayer, C. R.; Mialane, P. Hybrid Organic-Inorganic Polyoxometalate Compounds: From Structural Diversity to Applications. Chem. Rev. 2010, 110, 6009-6048.

17. Santoni, M.-P.; Hanan, G. S.; Hasenknopf, B. Covalent Multi-Component Systems of Polyoxometalates and Metal Complexes: Toward Multi-Functional Organic-Inorganic Hybrids in Molecular and Material Sciences. Coord. Chem. Rev. 2014, 281, 64-85.

18. Matt, B.; Coudret, C.; Viala, C.; Jouvenot, D.; Loiseau, F.; Izzet, G.; Proust, A. Elaboration of Covalently Linked Polyoxometalates with Ruthenium and Pyrene Chromophores and Characterisation of Their Photophysical Properties. Inorg. Chem. 2011, 50, 7761-7768.

19. Matt, B.; Moussa, J.; Chamoreau, L.-M.; Afonso, C.; Proust, A.; Amouri, H.; Izzet, G. Elegant Approach to the Synthesis of a Unique Heteroleptic Cyclometalated Iridium(III)-Polyoxometalate Conjugate. Organometallics 2012, 31, 35-38.

20. Bi, L.-H.; Kortz, U.; Keita, B.; Nadjo, L. The Ruthenium(II)-Supported Heteropolytungstates $\left[\mathrm{Ru}(\mathrm{dmsO})_{3}\left(\mathrm{H}_{2} \mathrm{O}\right) \mathrm{XW}_{11} \mathrm{O}_{39}\right]^{6-}(\mathrm{X}=\mathrm{Ge}, \mathrm{Si})$. Dalton Trans. 2004, 3184-3190.

21. Bar-Nahum, I.; Neumann, R. Synthesis, Characterization and Catalytic Activity of a Wilkinson's Type MetalOrganic-Polyoxometalate Hybrid Compound. Chem. Commun. 2003, 2690-2691.

22. Bar-Nahum, I.; Cohen, H.; Neumann, R. Organometallic-Polyoxometalate Hybrid Compounds: Metallosalen Compounds Modified by Keggin Type Polyoxometalates. Inorg. Chem. 2003, 42, 3677-3684.

23. Rinfray, C.; Izzet, G.; Pinson, J.; Gam Derouich, S.; Ganem, J.-J.; Combellas, C.; Kanoufi, F.; Proust, A. Electrografting of Diazonium-Functionalized Polyoxometalates: Synthesis, Immobilisation and Electron-Transfer Characterisation from Glassy Carbon. Chem. - Eur. J. 2013, 19, 13838-13846.

24. Guo, Y.; Hu, C. Heterogeneous Photocatalysis by Solid Polyoxometalates. J. Mol. Catal. A: Chem. 2007, 262, 136-148.

25. Yang, Y.; Guo, Y.; Hu, C.; Wang, Y.; Wang, E. Preparation of Surface Modifications of Mesoporous Titania with Monosubstituted Keggin Units and their Catalytic Performance for Organochlorine Pesticide and Dyes under UV Irradiation. Appl. Catal., A: Gen. 2004, 273, 201-210.

26. Mandic, S.; Healey, M. R.; Gotthardt, J. M.; Alley, K. G.; Gable, R. W.; Ritchie, C.; Boskovic, C. A Polyoxometalate-Based Coordination Polymer with the Diamondoid Topology. Eur. J. Inorg. Chem. 2013, 2013, 16311634.

27. Du, D. Y.; Qin, J. S.; Li, S. L.; Su, Z. M.; Lan, Y. Q. Recent Advances in Porous Polyoxometalate-Based MetalOrganic Framework Materials. Chem. Soc. Rev. 2014, 43, 4615-4632.

28. Canny, J.; Tézé, A.; Thouvenot, R.; Hervé, G. Disubstituted Tungstosilicates. 1. Synthesis, Stability, and Structure of the Lacunary Precursor Polyanion of a Tungstosilicate $\mathrm{Y}_{-} \mathrm{SiW}_{10} \mathrm{O}_{36}{ }^{8-}$. Inorg. Chem. 1986, 25, 2114-2119.

29. Knoth, W. H.; Harlow, R. L. New Tungstophosphates: $\mathrm{Cs}_{6} \mathrm{~W}_{5} \mathrm{P}_{2} \mathrm{O}_{23}, \mathrm{Cs}_{7} \mathrm{~W}_{10} \mathrm{PO}_{36}$, and $\mathrm{Cs}_{7} \mathrm{Na}_{2} \mathrm{~W}_{10} \mathrm{PO}_{37}$. J. Am. Chem. Soc. 1981, 103, 1865-1867.

30. Contant, R.; Tézé, A. A New Crown Heteropolyanion $\mathrm{K}_{28} \mathrm{Li}_{5} \mathrm{H}_{7} \mathrm{P}_{8} \mathrm{~W}_{48} \mathrm{O}_{184} \cdot 92 \mathrm{H}_{2} \mathrm{O}$ : Synthesis, Structure, and Properties. Inorg. Chem. 1985, 24, 4610-4614.

31. Marrot, J.; Pilette, M. A.; Haouas, M.; Floquet, S.; Taulelle, F.; López, X.; Poblet, J. M.; Cadot, E. Polyoxometalates Paneling through $\left\{\mathrm{Mo}_{2} \mathrm{O}_{2} \mathrm{~S}_{2}\right\}$ Coordination: Cation-Directed Conformations and Chemistry of a Supramolecular Hexameric Scaffold. J. Am. Chem. Soc. 2012, 134, 1724-1737.

32. Kirby, J. F.; Baker, L. C. W. Effects of Counterions in Heteropoly Electrolyte Chemistry. 1. Evaluations of Relative Interactions by NMR on Kozik Salts. Inorg. Chem. 1998, 37, 5537-5543.

33. Grigoriev, V. A.; Cheng, D.; Hill, C. L.; Weinstock, I. A. Role of Alkali Metal Cation Size in the Energy and Rate of Electron Transfer to Solvent-Separated 1:1 $\left[\left(\mathrm{M}^{+}\right)(\right.$Acceptor $\left.)\right]\left(\mathrm{M}^{+}=\mathrm{Li}^{+}, \mathrm{Na}^{+}, \mathrm{K}^{+}\right)$Ion Pairs. J. Am. Chem. Soc. 2001, 123, 5292-5307. 
34. Grigoriev, V. A.; Hill, C. L.; Weinstock, I. A. Role of Cation Size in the Energy of Electron Transfer to 1:1 Polyoxometalate Ion Pairs $\left\{\left(\mathrm{M}^{+}\right)\left(\mathrm{X}^{n+} \mathrm{VW}_{11} \mathrm{O}_{40}\right)\right\}^{(8-n)-}(\mathrm{M}=\mathrm{Li}, \mathrm{Na}, \mathrm{K})$. J. Am. Chem. Soc. 2000, 122, 3544-3545.

35. Volkmer, D.; Bredenkötter, B.; Tellenbröker, J.; Kögerler, P.; Kurth, D. G.; Lehmann, P.; Schnablegger, H.; Schwahn, D.; Piepenbrink, M.; Krebs, B. Structure and Properties of the Dendron-Encapsulated Polyoxometalate $\left(\mathrm{C}_{52} \mathrm{H}_{60} \mathrm{NO}_{12}\right)_{12}\left[\left(\mathrm{M}_{n}\left(\mathrm{H}_{2} \mathrm{O}\right)\right)_{3}\left(\mathrm{SbW}_{9} \mathrm{O}_{33}\right)_{2}\right]$, a First Generation Dendrizyme. J. Am. Chem. Soc. 2002, 124, 10489-10496.

36. Nlate, S.; Jahier, C. Dendritic Polyoxometalate Hybrids: Efficient and Recoverable Catalysts for Oxidation Reactions. Eur. J. Inorg. Chem. 2013, 2013, 1606-1619.

37. Li, B.; Zhang, J.; Wang, S.; Li, W.; Wu, L. Nematic Ion-Clustomesogens from Surfactant-Encapsulated Polyoxometalate Assemblies. Eur. J. Inorg. Chem. 2013, 2013, 1869-1875.

38. Wu, Y.; Shi, R.; Wu, Y.-L.; Holcroft, J. M.; Liu, Z.; Frasconi, M.; Wasielewski, M. R.; Li, H.; Stoddart, J. F. Complexation of Polyoxometalates with Cyclodextrins. J. Am. Chem. Soc. 2015, 137, 4111-4118.

39. Chiang, M.-H.; Dzielawa, J. A.; Dietz, M. L.; Antonio, M. R. Redox Chemistry of the Keggin Heteropolyoxotungstate Anion in Ionic Liquids. J. Electroanal. Chem. 2004, 567, 77-84.

40. Rickert, P. G.; Antonio, M. R.; Firestone, M. A.; Kubatko, K.-A.; Szreder, T.; Wishart, J. F.; Dietz, M. L. Tetraalkylphosphonium Polyoxometalate Ionic Liquids: Novel, Organic-Inorganic Hybrid Materials. J. Phys. Chem. B 2007, 111, 4685-4692.

41. Wang, R.; Jia, D.; Cao, Y. Facile Synthesis and Enhanced Electrocatalytic Activities of Organic-Inorganic Hybrid Ionic Liquid Polyoxometalate Nanomaterials by Solid-State Chemical Reaction. Electrochim. Acta 2012, 72, $101-107$.

42. Floquet, S.; Terazzi, E.; Korenev, V. S.; Hijazi, A.; Guénée, L.; Cadot, E. Layered lonic Liquid-Crystalline Organisations Built from Nano-Capsules $\left[\mathrm{Mo}_{132} \mathrm{O}_{312} \mathrm{~S}_{60}\left(\mathrm{SO}_{4}\right) x\left(\mathrm{H}_{2} \mathrm{O}\right)_{132-2 x}\right]^{(12+2 x)-}$ and DODA Cations. Liq. Cryst. 2014, 41, 1000-1007.

43. Liu, S.; Volkmer, D.; Kurth, D. Functional Polyoxometalate Thin Films via Electrostatic Layer-by-Layer SelfAssembly. Journal of Cluster Science 2003, 14, 405-419.

44. Fontananova, E.; Donato, L.; Drioli, E.; Lopez, L. C.; Favia, P.; d'Agostino, R. Heterogenization of Polyoxometalates on the Surface of Plasma-Modified Polymeric Membranes. Chem. Mater. 2006, 18, 1561-1568.

45. Verhoeff, A. A.; Kistler, M. L.; Bhatt, A.; Pigga, J.; Groenewold, J.; Klokkenburg, M.; Veen, S.; Roy, S.; Liu, T.; Kegel, W. K. Charge Regulation as a Stabilization Mechanism for Shell-Like Assemblies of Polyoxometalates. Phys. Rev. Lett. 2007, 99, 066104-066107.

46. Schmitz, K. S. Macroion Clustering in Solutions and Suspensions: The Roles of Microions and Solvent. J. Phys. Chem. B 2009, 113, 2624-2638.

47. Favette, S.; Hasenknopf, B.; Vaissermann, J.; Gouzerh, P.; Roux, C. Assembly of a Polyoxometalate into an Anisotropic Gel. Chem. Commun. 2003, 2664-2665.

48. Liu, G.; Liu, T. Thermodynamic Properties of the Unique Self-Assembly of $\left\{\mathrm{Mo}_{72} \mathrm{Fe}_{30}\right\}$ Inorganic Macro-lons in Salt-Free and Salt-Containing Aqueous Solutions. Langmuir 2005, 21, 2713-2720.

49. López, X.; Carbó, J. J.; Bo, C.; Poblet, J. M. Structure, Properties and Reactivity of Polyoxometalates: A Theoretical Perspective. Chem. Soc. Rev. 2012, 41, 7537-7571.

50. Chermette, H.; Lefebvre, F. Theoretical Study of the Four Isomers of $\left[\mathrm{SiW}_{11} \mathrm{O}_{39}\right]^{8-}$ : Structure, Stability and Physical Properties. C. R. Chim. 2012, 15, 143-151.

51. Laurencin, D.; Proust, A.; Gérard, H. Theoretical Study of the Relative Stabilities of the $\alpha / \beta_{3}-\left[\mathrm{XW}_{11} \mathrm{O}_{39}\right]^{m-}$ Lacunary Polyoxometalates (X = P, Si). Inorg. Chem. 2008, 47, 7888-7893.

52. López, X.; Maestre, J. M.; Bo, C.; Poblet, J.-M. Electronic Properties of Polyoxometalates: A DFT Study of $\alpha / \beta-$ $\left[\mathrm{XM}_{12} \mathrm{O}_{40}\right]^{n-}$ Relative Stability ( $\mathrm{M}=\mathrm{W}$, Mo and X a Main Group Element). J. Am. Chem. Soc. 2001, 123, 9571-9576.

53. Zhang, F.-Q.; Zhang, X.-M.; Wu, H.-S.; Jiao, H. Structural and Electronic Properties of Hetero-Transition-Metal Keggin Anions: A DFT Study of $\alpha / \beta-\left[\mathrm{XW}_{12} \mathrm{O}_{40}\right]^{n-}\left(\mathrm{X}=\mathrm{Cr}^{\mathrm{VI}}, \mathrm{V}^{\mathrm{V}}, \mathrm{Ti}^{\mathrm{IV}}, \mathrm{Fe}^{\mathrm{III}}, \mathrm{Co}^{\prime \prime \prime}, \mathrm{Ni} \mathrm{II}^{\mathrm{II}}, \mathrm{Co}\right.$, , and Zn") Relative Stability. J. Phys. Chem. A 2007, 111, 159-166.

54. Zhang, F.-Q.; Wu, H.-S.; Qin, X.-F.; Li, Y.-W.; Jiao, H. On the $\alpha / \beta-\left[A \mid W_{12} \mathrm{O}_{40}\right]^{5-}$ Stability: Revisited. J. Mol. Struct. (THEOCHEM) 2005, 755, 113-117.

55. López, X.; Poblet, J. M. DFT Study on the Five Isomers of $\mathrm{PW}_{12} \mathrm{O}_{40}{ }^{3-}$ : Relative Stabilization upon Reduction. Inorg. Chem. 2004, 43, 6863-6865.

56. Fernández, J. A.; López, X.; Poblet, J. M. A DFT Study on the Effect of Metal, Anion Charge, Heteroatom and Structure upon the Relative Basicities of Polyoxoanions. J. Mol. Catal. A: Chem. 2007, 262, 236-242.

57. López, X.; Bo, C.; Poblet, J. M. Electronic Properties of Polyoxometalates: Electron and Proton Affinity of Mixed-Addenda Keggin and Wells-Dawson Anions. J. Am. Chem. Soc. 2002, 124, 12574-12582.

58. López, X.; Weinstock, I. A.; Bo, C.; Sarasa, J. P.; Poblet, J. M. Structural Evolution in Polyoxometalates: A DFT Study of Dimerization Processes in Lindqvist and Keggin Cluster Anions. Inorg. Chem. 2006, 45, 6467-6473. 
59. Maestre, J. M.; Lopez, X.; Bo, C.; Poblet, J.-M.; Casañ-Pastor, N. Electronic and Magnetic Properties of $\alpha-K e g g i n$

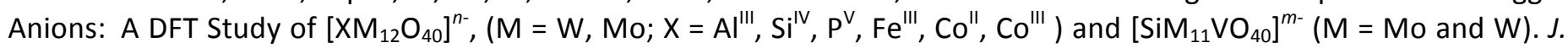
Am. Chem. Soc. 2001, 123, 3749-3758.

60. Maestre, J. M.; Poblet, J. M.; Bo, C.; Casañ-Pastor, N.; Gomez-Romero, P. Electronic Structure of the Highly Reduced Polyoxoanion $\left[\mathrm{PMo}_{12} \mathrm{O}_{40}(\mathrm{VO})_{2}\right]^{5-}:$ A DFT Study. Inorg. Chem. 1998, 37, 3444-3446.

61. Vilà-Nadal, L.; Rodríguez-Fortea, A.; Poblet, J. M. Theoretical Analysis of the Possible Intermediates in the Formation of $\left[\mathrm{W}_{6} \mathrm{O}_{19}\right]^{2-}$. Eur. J. Inorg. Chem. 2009, 2009, 5125-5133.

62. Aparicio, P. A.; Poblet, J. M.; López, X. Tungsten Redox Waves in $\left[\mathrm{XMW}_{11} \mathrm{O}_{40}\right]^{n-}(\mathrm{X}=\mathrm{P}, \mathrm{Si}, \mathrm{Al}$ and $\mathrm{M}=\mathrm{W}, \mathrm{Mo}, \mathrm{V}$, $\mathrm{Nb}, \mathrm{Ti})$ Keggin Compounds - Effect of Localised/Delocalised Charges. Eur. J. Inorg. Chem. 2013, 2013, $1910-1916$.

63. Bridgeman, A. J. Computational Study of the Vibrational Spectra of $\alpha$ - and $\beta$-Keggin Polyoxometalates. Chem. Eur. J. 2004, 10, 2935-2941.

64. Brodbeck, R.; Tönsing, T.; Andrae, D.; Volkmer, D. Molecular Dynamics Simulations of Dendrimer-Encapsulated $\alpha$-Keggin Ions in Trichloromethane Solution. J. Phys. Chem. B 2008, 112, 5153-5162.

65. López, X.; Nieto-Draghi, C.; Bo, C.; Bonet Ávalos, J.; Poblet, J. M. Polyoxometalates in Solution: Molecular Dynamics Simulations on the $\alpha-\mathrm{PW}_{12} \mathrm{O}_{40}{ }^{3-}$ Keggin Anion in Aqueous Media. J. Phys. Chem. A 2005, 109, 1216-1222.

66. Leroy, F.; Miró, P.; Poblet, J. M.; Bo, C.; Bonet Ávalos, J. Keggin Polyoxoanions in Aqueous Solution: lon Pairing and Its Effect on Dynamic Properties by Molecular Dynamics Simulations. J. Phys. Chem. B 2008, 112, 8591-8599.

67. Chaumont, A.; Wipff, G. Ion Aggregation in Concentrated Aqueous and Methanol Solutions of Polyoxometallates Keggin Anions: The Effect of Counterions Investigated by Molecular Dynamics Simulations. Phys. Chem. Chem. Phys. 2008, 10, 6940-6953.

68. Chaumont, A.; Wipff, G. Do Keggin Anions Repulse Each Other in Solution? The Effect of Solvent, Counterions and Ion Representation Investigated by Free Energy (PMF) Simulations C. R. Chim. 2012, 15, 107-117.

69. Chaumont, A.; Wipff, G. Interactions between Keggin Anions in Water: The Higher Their Charge, the Higher Their Condensation? A Simulation Study. Eur. J. Inorg. Chem. 2013, 2013, 1835-1853.

70. Bera, M. K.; Qiao, B.; Seifert, S.; Burton-Pye, B. P.; Olvera de la Cruz, M.; Antonio, M. R. Aggregation of Heteropolyanions in Aqueous Solutions Exhibiting Short-Range Attractions and Long-Range Repulsions. J. Phys. Chem. C 2016, 120, 1317-1327.

71. Mei, Y.; Huang, W.; Yang, Z.; Wang, J.; Yang, X., Ion-Pairing and Aggregation of lonic Liquid-Neutralized Polyoxometalate Salts in Aqueous Solutions. In Fluid Phase Equilibria, Elsevier Ltd: 2016; Vol. 425, pp 31-39.

72. Frisch, M. J.; Trucks, G. W.; Schlegel, H. B.; Scuseria, G. E.; Robb, M. A.; Cheeseman, J. R.; Scalmani, G.; Barone, V.; Mennucci, B.; Petersson, G. A., et al. Gaussian 09, Rev. D.01; Gaussian, Inc.: Wallingford, CT, USA, 2009.

73. Becke, A. D. Density-Functional Exchange-Energy Approximation with Correct Asymptotic Behavior. Phys. Rev. A 1988, 38, 3098-3100.

74. Perdew, J. P. Density-Functional Approximation for the Correlation Energy of the Inhomogeneous Electron Gas. Phys. Rev. B 1986, 33, 8822-8824.

75. Hay, P. J.; Wadt, W. R. Ab initio Effective Core Potentials for Molecular Calculations - Potentials for K to Au Including the Outermost Core Orbitals. J. Chem. Phys. 1985, 82, 299-310.

76. Tomasi, J.; Mennucci, B.; Cammi, R. Quantum Mechanical Continuum Solvation Models. Chem. Rev. 2005, 105, 2999-3094.

77. Dang, L. X. Development of Nonadditive Intermolecular Potentials Using Molecular Dynamics: Solvation of Li ${ }^{+}$ and $\mathrm{F}^{-}$ions in polarizable water. J. Chem. Phys. 1992, 96, 6970-6977.

78. Jorgensen, W. L.; Chandrasekhar, J.; Madura, J. D.; Impey, R. W.; Klein, M. L. Comparison of Simple Potential Functions for Simulating Liquid Water. J. Chem. Phys. 1983, 79, 926-935.

79. Miyamoto, S.; Kollman, P. A. Settle: An Analytical Version of the SHAKE and RATTLE Algorithm for Rigid Water Models. J. Comput. Chem. 1992, 13, 952-962.

80. Rudolph, W.; Brooker, M. H.; Pye, C. C. Hydration of Lithium Ion in Aqueous Solutions. J. Phys. Chem. 1995, 99, 3793-3797.

81. Pronk, S.; Páll, S.; Schulz, R.; Larsson, P.; Bjelkmar, P.; Apostolov, R.; Shirts, M. R.; Smith, J. C.; Kasson, P. M.; van der Spoel, D., et al. GROMACS 4.5: A High-Throughput and Highly Parallel Open Source Molecular Simulation Toolkit. Bioinformatics 2013, 29, 845-854.

82. Van Der Spoel, D.; Lindahl, E.; Hess, B.; Groenhof, G.; Mark, A. E.; Berendsen, H. J. C. GROMACS: Fast, Flexible, and Free. J. Comput. Chem. 2005, 26, 1701-1718.

83. Berendsen, H. J. C.; Postma, J. P. M.; Vangunsteren, W. F.; Dinola, A.; Haak, J. R. Molecular Dynamics with Coupling to an External Bath. J. Chem. Phys. 1984, 81, 3684-3690. 
84. Darden, T.; York, D.; Pedersen, L. Particle Mesh Ewald - an Nlog(N) Method for Ewald Sums in Large Systems. J. Chem. Phys. 1993, 98, 10089-10092.

85. Hockney, R. W.; Goel, S. P.; Eastwood, J. W. Quiet High-Resolution Computer Models of a Plasma. J. Comput. Phys. 1974, 14, 148-158.

86. Humphrey, W.; Dalke, A.; Schulten, K. VMD: Visual Molecular Dynamics. J. Mol. Graphics 1996, $14,33-38$.

87. Keesom, W. H. The Second Virial Coefficient for Rigid Spherical Molecules, Whose Mutual Attraction is Equivalent to that of a Quadruplet Placed at their Centre. Proc. R. Neth. Acad. Arts Sci. 1915, 18, 636-646.

88. Mizuno, N.; Misono, M. Heterogeneous Catalysis. Chem. Rev. 1998, 98, 199-218.

89. Neiwert, W. A.; Cowan, J. J.; Hardcastle, K. I.; Hill, C. L.; Weinstock, I. A. Stability and Structure in $\alpha-$ and $\beta-$ Keggin Heteropolytungstates, $\left[\mathrm{X}^{n+} \mathrm{W}_{12} \mathrm{O}_{40}\right]^{(8-n)-}, \mathrm{X}=p$-Block Cation. Inorg. Chem. 2002, 41, 6950-6952. 


\section{TOC Graphic}

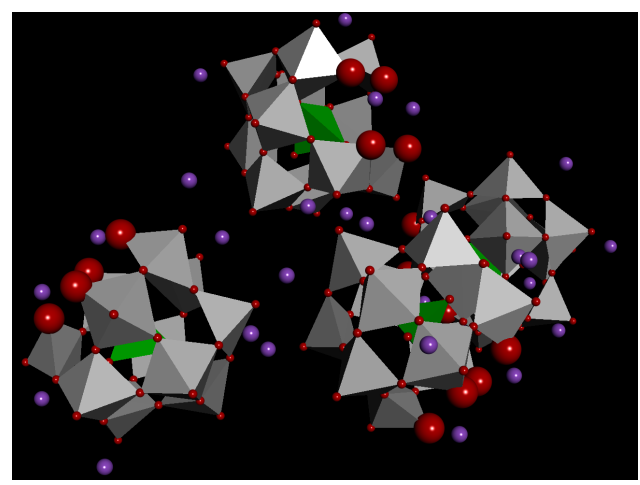

